\title{
CAMA
}

Centre for Applied Macroeconomic Analysis

\section{Does the central bank respond to credit market factors? A Bayesian DSGE approach}

\section{CAMA Working Paper 21/2015 June 2015}

Paul Kitney

Centre for Applied Macroeconomic Analysis (CAMA), ANU

\begin{abstract}
This paper estimates a version of a New Keynesian Dynamic Stochastic General Equilibrium model with financial frictions for the United States using Bayesian techniques. Various Henderson-McKibbin-Taylor style monetary policy rules are examined, which react to inflation, output and credit market factors including credit spreads, financial leverage and credit growth. The central question is whether the central bank responds to credit market factors in setting the policy interest rate, which is investigated using posterior odds tests. The paper explores whether there is evidence of stabilization, if indeed the central bank is responding to credit market factors. This is conducted using impulse response analysis and an examination of parameter posterior distributions. The most compelling result during the period under study is the US Fed responded to credit spreads in setting the policy rate. The empirical results also confirm that credit spreads offer stabilization benefits. This result is robust to variations in the policy rule. It is also found that while financial leverage improves model fit when included in the policy rule, the response is pro-cyclical, which would unlikely be a feature of stabilization policy. Finally, there is no evidence that the policy interest rate responded to credit growth.
\end{abstract}




\section{Keywords}

\section{JEL Classification}

\section{Address for correspondence:}

(E) cama.admin@anu.edu.au

The Centre for Applied Macroeconomic Analysis in the Crawford School of Public Policy has been established to build strong links between professional macroeconomists. It provides a forum for quality macroeconomic research and discussion of policy issues between academia, government and the private sector.

The Crawford School of Public Policy is the Australian National University's public policy school, serving and influencing Australia, Asia and the Pacific through advanced policy research, graduate and executive education, and policy impact. 


\title{
Does the Central Bank Respond to Credit Market Factors? A Bayesian DSGE Approach
}

\author{
Paul Kitney
}

December 1, 2014

\begin{abstract}
This paper estimates a version of a New Keynesian Dynamic Stochastic General Equilibrium model with financial frictions for the United States using Bayesian techniques. Various Henderson-McKibbin-Taylor style monetary policy rules are examined, which react to inflation, output and credit market factors including credit spreads, financial leverage and credit growth. The central question is whether the central bank responds to credit market factors in setting the policy interest rate, which is investigated using posterior odds tests. The paper explores whether there is evidence of stabilization, if indeed the central bank is responding to credit market factors. This is conducted using impulse response analysis and an examination of parameter posterior distributions. The most compelling result during the period under study, is the US Fed responded to credit spreads in setting the policy rate. The empirical results also confirm that credit spreads offer stabilization benefits. This result is robust to variations in the policy rule. It is also found that while financial leverage improves model fit when included in the policy rule, the response is pro-cyclical, which would unlikely be a feature of stabilization policy. Finally, there is no evidence that the policy interest rate responded to credit growth.
\end{abstract}




\section{Introduction}

\subsection{Overview}

The Global Financial Crisis (GFC) highlighted the extreme case of how financial sector stress, via rising costs of credit, lack of availability or rationing of the volume of credit away from segments of the economy and the systemic risk associated with this, can have meaningful real economy consequences. Since the GFC, the debate has been ongoing as to whether central banks should consider financial factors in setting monetary policy. It has been questioned whether systemic risk could have been avoided if the monetary authority paid more attention to possible risk factors in the credit market such as credit growth, overall financial leverage in the economy and the behaviour of credit spreads and well as asset prices. Ultimately, the debate led to the question as to whether financial factors should be considered in setting the policy, however, not just as part of crisis management but as a systematic component of conducting policy throughout the business cycle. The purpose of this paper is to contribute to this debate by investigating empirically whether the central bank has been targeting financial factors and in particular whether the US monetary policy makers responded to credit market factors in setting the policy interest rate.

The approach is to a estimate a New Keynesian Dynamic Stochastic General Equilibrium (DSGE) model with financial frictions for the United States, using Bayesian techniques. Within this framework, alternative Henderson-McKibbin-Taylor (HMT) (Henderson and McKibbin 1993) (Taylor 1993) style monetary policy rules are examined, which react to inflation, output and credit market factors including credit spreads, financial leverage and credit growth. The core question of whether the central bank responds to credit market factors in setting the policy interest rate is conducted using posterior odds tests. The policy rule parameters are estimated, not in isolation but simultaneously with the DSGE parameter set. This allows for studies of shock propagation and impulse response analysis and avoids some problems with misspecification and identification experienced with other methods. There is also an investigation into whether there is evidence of stabilization, if indeed the central bank is responding to credit market factors. This is conducted using impulse response analysis and an examination of parameter posterior distributions. 


\subsection{Related Literature}

A variant of a New Keynesian DSGE model (Kaihatsu and Kurozumi 2014) is modified and used as the modelling framework. It follows Bernanke, Gertler and Gilchrist (1999) in that it contains the financial accelerator mechanism but it belongs to a more recent class of models that are designed for empirical analysis and include financial sector shocks, such as shock to the external finance premium (EFP) and net worth shocks. Both Christiano, Motto and Rostagno (2010) and Gilchrist, Ortiz and Zakrajsek (2009) belong to this class, they contain the financial accelerator, are structural models, contain a different set of shock variables and have a different emphasis. For example, the key financial shock used in Christiano et al. (2010) is a risk shock which is a shock to the variance of idiosyncratic productivity of entrepreneurs and Christiano et al. (2010), which differs from the financial shock, EFP shock employed in Kaihatsu and Kurozumi (2014). Gilchrist et al. (2009) emphasizes bond market information measures to help identify the financial accelerator and show that it empirically explains business fluctuations well, whereas Kaihatsu and Kurozumi (2014) shows empirically that financial factors go a long way towards explaining the business cycle.

The Bayesian estimation methods employed follow An and Schorfheide (2007) with conventions followed from Smets and Wouters (2007) with respect to Bayesian DSGE estimation. For the specific literature concerned with estimating HMT rules within a DSGE model using Bayesian methods, the closest study is Lubik and Schorfheide (2007). The main differences are that Lubik and Schorfheide (2007) uses a smaller scale model and the question addressed is whether central banks target exchange rates in monetary policy rules as opposed to slightly larger scale model and an emphasis on credit factor targeting in this paper. Apart from that, the approach of comparing models using a posterior odds, is a similar methodology.

There is an emerging literature on the extended monetary policy rules that include credit market factors. Curdia and Woodford (2010) modify a monetary policy rule to include cases of a response to the economy wide volume of credit and also to credit spreads. The credit spread adjustment improves upon the simple monetary policy rule but the results are less encouraging for responding to credit volume. Following the GFC, Taylor (2008) recommended adjustments to monetary policy rules to the U.S. House of Representatives that would adjust for financial stress, where a credit spread was the preferred measure of 
financial stress advocated.

Gilchrist and Zakrajsek (2012) construct a credit spread index, the GZ credit spread which they claim has high predictive power for economic activity. Following the methodology from Gilchrist and Zakrajsek (2012), Gilchrist and Zakrajsek (2011), present a credit spread augmented monetary policy rule, which effectively dampens the negative effects on economic activity emanating from credit supply shocks, with only a modest increase in inflation.

\subsection{Key Findings}

The most important result is that over the the time period tested, the US central bank responded to credit spreads in setting the policy rate. The empirical results also confirm that credit spreads offer stabilization benefits. This result is robust to variations in the policy rule. It is also found that while financial leverage improves model fit when included in the policy rule, the response is pro-cyclical, which would unlikely be a feature of stabilization policy. Finally, there is no evidence that the policy interest rate responded to credit growth.

\subsection{Organizational Plan}

Next, in Section 2, is a detailed presentation of the DSGE model used for estimation followed by the empirical results in Section 3, which outlines the estimation strategy. Here there is a summary of the estimated model, an outline of the Bayesian methodology employed in the estimation and empirical analysis in general, a data description and the estimation results. This is followed up by robustness tests for the results and the impulse response analysis. Finally, in Section 4, there are some concluding remarks.

\section{Model}

The model chosen to address the central question is whether monetary authorities respond to credit factors in setting the the policy interest rate is a modified version of Bernanke et al. (1999) employed by Kaihatsu and Kurozumi (2014), for estimation using Bayesian methods. The agents embodied in the Kaihatsu and Kurozumi (2014) model consist of households, workers, entrepreneurs, financial intermediaries, intermediate-good firms, consumption-good firms, investment-good firms, capital-good firms and a central bank. Kaihatsu and Kurozumi 
(2014) principal modifications to Bernanke et al. (1999) include the addition of financial sector shocks to the external finance premium and net worth and distinguish between technology specific and technology neutral shocks. To follow is an outline of each representative agent's optimization problem and the log-linearized Kaihatsu and Kurozumi (2014) first order and equilibrium conditions.

\subsection{Households}

The household sector is represented by a continuum of members $m \in[0,1]$ where some members are workers and others are entrepreneurs. For simplicity, all members pool consumption and have joint consumption and savings decisions. Positive utility is derived from consumption goods $\left(C_{t}\right)$ and negative utility from supplying labor $\left(h_{t}(m)\right)$ to intermediate goods firms $f \in[0,1]$, where $h_{t}(m)=\int_{0}^{1} h_{t}(m, f) d f$. The household's utility maximization problem is given by the following. The household problem is therefore:

$$
\max _{C_{t}, D_{t}} \mathrm{E}_{0} \sum_{t=0}^{\infty} \beta^{t} \exp \left(z_{t}^{b}\right)\left[\frac{\left(C_{t}-\theta C_{t-1}\right)^{1-\sigma}}{1-\sigma}-\left(Z_{t}^{*}\right)^{1-\sigma} \exp \left(z_{t}^{h}\right) \int_{0}^{1} \frac{h_{t}(m)^{1+\chi}}{1+\chi} d m\right]
$$

subject to the household budget constraint

$$
P_{t} C_{t}+D_{t}=r_{t-1}^{n} D_{t-1}+P_{t} \int_{0}^{1} W_{t}(m) h_{t}(m) d m+T_{t}
$$

In the objective function, $\beta \in(0,1)$ is the subjective discount factor, $\sigma>0$ is the degree of relative risk aversion, $\theta \in[0,1]$ is habit persistence in consumption preferences, $\chi>0$ is the inverse of the elasticity of labor supply, $z_{t}^{b}$ is the intertemporal preference shock and $z_{t}^{h}$ is a labor supply shock. The labor dis-utility term contains $Z_{t}^{*}$, which is the composite technological level used to ensure the existence of a balanced growth path in the model. In the budget constraint, $P_{t}$ denotes the price of consumption goods, $D_{t}$ represents deposits in the financial intermediaries and $r_{t}^{n}$ is the gross nominal interest rate, which is regarded as the monetary policy rate. $W_{t}(m)$ is worker m's real wage and $T_{t}$ consists of profits from firms and a lump sum public transfer to households. The first order conditions for consumption 
and deposits in log-linear form are

$$
\begin{array}{r}
\hat{\lambda}_{t}=-\frac{1}{1-\beta \theta\left(z^{*}\right)^{-\sigma}}\left\{\frac{\sigma}{1-\frac{\theta}{z^{*}}}\left[\hat{c}_{t}-\frac{\theta}{z^{*}}\left(\hat{c}_{t-1}-z_{t}^{*}\right)\right]-z_{t}^{b}\right\} \\
+\frac{\beta \theta\left(z^{*}\right)^{-\sigma}}{1-\beta \theta\left(z^{*}\right)^{-\sigma}}\left\{\frac{\sigma}{1-\frac{\theta}{z^{*}}}\left(E_{t} \hat{c}_{t+1}+E_{t} z_{t+1}^{*}-\frac{\theta}{z^{*}} \hat{c}_{t}\right)-E_{t} z_{t+1}^{b}\right\}
\end{array}
$$

and

$$
\hat{\lambda_{t}}=E_{t} \hat{\lambda}_{t+1}-\sigma E_{t} z_{t+1}^{*}+\hat{r}_{t}^{n}-E_{t} \hat{\pi}_{t+1}
$$

respectively ${ }^{1}$, where $\lambda_{t}$ is the marginal utility of consumption and $\pi_{t}=\frac{P_{t}}{P_{t}-1}$ is the gross consumption good inflation rate.

\subsection{Workers}

Monopolistic competition in the intermediate-good firm sector implies the demand for labor services by worker $\mathrm{m}$ is given by $h_{t}(m)=h_{t}\left(\frac{W_{t}(m)}{W_{t}}\right)^{-\theta_{t}^{w}}$, where $h_{t}=\left[\int_{0}^{1}\left(h_{t}(m)\right)^{\frac{\theta_{t}^{w}-1}{\theta_{t}^{w}}} d m\right]^{\frac{\theta_{t}^{w}}{\theta_{t}^{w}-1}}$ is aggregate labor service and the elasticity of substitution, $\theta_{t}^{w}>1$. The real wage is:

$$
W_{t}=\left[\int_{0}^{1}\left(W_{t}(m)\right)^{1-\theta_{t}^{w}} d m\right]^{\frac{1}{1-\theta_{t}^{w}}}
$$

Using Calvo Pricing (Calvo 1983), nominal rigidities are included by way of staggered wages, $P_{t} W_{t}$. A fraction of wages, $1-\xi \in(0,1)$ is re-optimized in each period, while the remainder $\xi$ is indexed to the steady state growth rate, $z^{*}$ and and a weighted average of past and steady state inflation rates, $\pi_{t-1}^{\gamma_{w}} \pi^{1-\gamma_{w}}$. The term $\gamma_{w} \in[0,1]$ is the relative weight on past inflation. Wages are then re-optimized in period-t given the following constrained

\footnotetext{
${ }^{1}$ The convention of upper case letters for original variables and lower case for log-linear terms is followed throughout.
} 
optimization problem:

$$
\begin{array}{r}
\max _{W_{t}^{o}} \mathrm{E}_{0} \sum_{j=0}^{\infty}\left(\beta \xi_{w}\right)^{j}\left[\Lambda_{t+j} h_{t+j \mid t}(m) \frac{P_{t} W_{t}(m)}{P_{t+j}} \prod_{k=1}^{j}\left(z^{*} \pi_{t+k-1}^{\gamma_{w}} \pi^{1-\gamma_{w}}\right)-\right. \\
\left.\frac{\exp \left(z_{t+j}^{b}\right)\left(Z_{t+j}^{*}\right)^{1-\sigma} \exp \left(z_{t+j}^{h}\right)\left(h_{\left.t+j \mid t(m))^{1+\chi}\right)}\right.}{1+\chi}\right]
\end{array}
$$

subject to

$$
h_{t+j \mid t(m)}=h_{t+j}\left[\frac{P_{t} W_{t}(m)}{P_{t+j} W_{t+j}} \prod_{k=1}^{j}\left(z^{*} \pi_{t+k-1}^{\gamma_{w}} \pi^{1-\gamma_{w}}\right)\right]
$$

The first order condition for the re-optimized real wage $W_{t}^{o}$, substituted into the aggregate real wage equation (3) and log-linearized, yields

$$
\begin{array}{r}
\hat{w}_{t}=\hat{w}_{t-1}-\hat{\pi}_{t}-\gamma_{w} \hat{\pi}_{t-1}-z_{t}^{*}+\beta\left(z^{*}\right)^{1-\sigma}\left(E_{t} \hat{w}_{t+1}-\hat{w}_{t}+E_{t} \hat{\pi}_{t+1}-\gamma_{w} \hat{\pi}_{t}+E_{t} z_{t+1}^{*}\right) \\
+\frac{\left(1-\xi_{w}\right)\left(1-\beta\left(z^{*}\right)^{1-\sigma} \xi_{w}\right)}{\xi_{w}\left[1+\frac{1+\lambda^{w}}{\lambda^{w}}\right]}\left(\chi \hat{h}_{t}-\hat{\lambda}_{t}-\hat{w}_{t}+z_{t}^{b}\right)+z_{t}^{w}
\end{array}
$$

, noting that $\lambda_{t}^{w}=\frac{1}{\theta_{t}^{w}-1}>0$ and the wage shock, $z_{t}^{w}$ is a composite of $z_{t}^{h}$ and $\lambda_{t}^{w}$ (Kaihatsu and Kurozumi 2014)[p.231].

\subsection{Entrepreneurs and Financial Intermediaries}

In the Kaihatsu and Kurozumi (2014) model the entrepreneurs adjust the utilization rate $u_{t}$ on capital at the end of the previous period $K_{t-1}$ bought at the real price $Q_{t-1}$ from capital good firms. They provide capital services $u_{t} K_{t-1}$ at a real rental rate of capital $R_{t}^{k}$ for the intermediate goods firms. Capital is depreciated at the rate $\delta\left(u_{t}\right)$, where $\delta^{\prime}>0$, $\delta^{\prime \prime}>0, \delta(1)=\delta \in(0,1)$ and $\frac{\delta^{\prime}(1)}{\delta^{\prime \prime}(1)}=\tau>0$. The entrepreneurs then sell the residual capital $\left.\left(1-\delta\left(u_{t}\right)\right) K_{t-1}\right)$ to capital goods firms at price $Q_{t}$. The first order condition for the optimal capitalization rate is $R_{t}^{k}=Q_{t} \delta^{\prime}\left(u_{t}\right)$ or in log-linear form,

$$
\hat{u}_{t}=\tau\left(\hat{r}_{t}^{k}-\hat{q}_{t}\right)
$$


The entrepreneurs purchase capital using a combination of net worth $N_{t}$ and a loan amount $L_{t}$, which is provided by the financial intermediaries and is displayed in log-linear form,

$$
\hat{l_{t}}=\frac{1+\lambda^{i}}{1+\lambda^{i}-\frac{n}{k}}\left(\hat{q_{t}}+\hat{k_{t}}\right)+\left(1-\frac{1+\lambda^{i}}{1+\lambda^{i}-\frac{n}{k}}\right) \hat{n_{t}} .
$$

The first order condition for optimal conditions for the purchase of capital in log-linear form is

$$
E_{t} \hat{r}_{t+1}^{E}=\left(1-\frac{1-\delta}{r^{E} \psi}\right) E_{t} \hat{r}_{t+1}^{k}+\frac{1-\delta}{r^{E} \psi} E_{t} \hat{q}_{t+1}-\hat{q}_{t}-E_{t} \hat{z}_{t+1}^{\psi}
$$

, where $E_{t} \hat{r}_{t+1}^{E}$ is the gross real loan rate and $z_{t}^{\psi}$ is the investment specific technology shock discussed in the investment-good firm section to follow.

The two equations that characterize the credit channel or financial accelerator in the Bernanke et al. (1999) sense (and indeed in Kaihatsu and Kurozumi (2014)), are the external finance premium and the evolution of net worth equation. The external finance premium, given by

$$
E_{t} \hat{r}_{t+1}^{E}=\hat{r}_{t}^{n}-E_{t} \hat{\pi}_{t+1}-\mu\left(\hat{n}_{t}-\hat{q}_{t}-\hat{k}_{t}\right)+z_{t}^{\mu}
$$

, is the spread between the gross real loan rate and the real risk free rate $\hat{r}_{t}{ }^{n}-E_{t} \hat{\pi}_{t+1}$, which is a positive function of the entrepreneur's leverage or borrowing requirement, $\hat{q}_{t}+\hat{k_{t}}-\hat{n_{t}}$, where $\mu \geq 0$ is the elasticity of the external finance premium to financial leverage and $z_{t}^{\mu}$ is the exogenous external finance premium shock.

Concomitant to the external finance premium equation in the shock propagation process inherent in the financial accelerator, is the evolution of net worth equation, which is the first order difference equation in net worth

$$
\begin{array}{r}
\hat{n}_{t}=\frac{\eta r^{E}}{z^{*}}\left\{\frac{1+\lambda^{i}}{\frac{n}{k}}\left[\left(1-\frac{1-\delta}{r^{E} \psi}\right) \hat{r}_{t}+\frac{1-\delta}{r^{E} \psi} \hat{q}_{t}-q_{t-1}-z_{t}^{\psi}\right]-\left(\frac{1+\lambda^{i}}{\frac{n}{k}}-1\right) E_{t-1} \hat{r}_{t}^{E}+n_{t-1}-z_{t}^{*}\right\} \\
+z_{t}^{\eta}
\end{array}
$$

, where $z_{t}^{\eta}$ is an exogenous shock to net worth. 


\subsection{Intermediate Good Firms}

In the Kaihatsu and Kurozumi (2014) framework, each intermediate-good firm $f \in[0,1]$ produces $Y_{t}(f)$ in output with labor and capital in inputs $\left\{h_{t}(f), K_{t}(f)\right\}$ at real rental rates $\left\{W_{t}, R_{t}^{k}\right\}$, respectively. The production function has the following form:

$$
Y_{t}(f)=\left(Z_{t} h_{t}(f)\right)^{1-\alpha}\left(K_{t}(f)\right)^{\alpha}-\phi y Z_{t}^{*}
$$

The term $Z_{t}$ denotes the level of neutral technology and in log notation follows an $\operatorname{AR}(1)$,

$$
\log Z_{t}=\log z+\log Z_{t-1}+z_{t}^{z}
$$

where $z_{t}^{z}$ represents a (non-stationary) neutral technology shock and $z>1$ is the gross steady state rate of technological change. The factor input for labor is the expression, $h_{t}(f)=$ $\left[\int_{0}^{1}\left(h_{t}(m, f)\right)^{\frac{\theta_{t}^{w}-1}{\theta_{t}^{w}}} d m\right]^{\frac{\theta_{t}^{w}}{\theta_{t}^{w}-1}}$ and $\alpha \in(0,1)$ denotes the capital elasticity of output. The last term in $(10),-\phi y Z_{t}^{*}$, is the output fixed costs. In order to establish a balanced growth path, output is de-trended such that de-trended output $y_{t}=\frac{Y_{t}}{Z_{t}^{*}}$, where $Z_{t}^{*}$ is the composite technology level, where $Z_{t}^{*}=Z_{t}\left(\Psi_{t}\right)^{\frac{\alpha}{1-\alpha}}$, where $\Psi_{t}$ denotes the level of IS technology and $\phi \in(0,1)$ is chosen so that the intermediate good's zero profit condition holds in steady state. The composite technological change, $\frac{Z_{t}^{*}}{Z_{t-1}^{*}}$ is the gross rate of balanced growth in the Kaihatsu and Kurozumi (2014) model with a steady state $z^{*}=z \psi^{\frac{\alpha}{1-\alpha}}$, where $\psi>1$ is the gross rate of IS technological change in steady state. Equating factor prices to marginal products for the optimal decisions by the two inputs leads to the equilibrium condition $\frac{1-\alpha}{\alpha}=\frac{W_{t} h_{t}}{R_{t}^{k} u_{t} K_{t-1}}$, where $h_{t}=\int_{0}^{1} h_{t}(f) d f$ and $u_{t} K_{t-1}=\int_{0}^{1} K_{t}(f) d f$. Now on the balanced growth path this equilibrium condition for the intermediate goods firms in log-linear terms is

$$
0=\hat{w}_{t}+\hat{h}_{t}-\left(\hat{r}_{t}+\hat{u}_{t}+\hat{k}_{t-1}-z_{t}^{*}-z_{t}^{\psi}\right)
$$

and the expression for real marginal cost is

$$
\hat{m} c_{t}=(1-\alpha) \hat{w}_{t}+\alpha \hat{r}_{t}^{k}
$$

, where $z_{t}^{*}=z_{t}^{z}+\frac{\alpha}{1-\alpha} z_{t}^{\psi}$ is the composite technology shock. 
The intermediate-good firm faces monopolistic competition so that firm-f faces a consumptiongood firms demand $Y_{t}(f)=Y_{t}\left(\frac{P_{t}(f)}{P_{t}}\right)^{-\theta_{t}^{p}}$. Here, $Y_{t}$ denotes the output of the consumptionfirm, $P_{t}(f)$, the differentiated price of the intermediate-good firm, which is staggered on a Calvo (1983) setting. Under Calvo pricing, the fraction $1-\xi_{p}$ of intermediate-good firms re-optimize prices while the remaining $\xi_{p}$ index to a weighted average of historical and steady state inflation rates given by $\pi_{t-1}^{\gamma_{p}} \pi^{1-\gamma_{p}}$. Here, $\gamma_{p} \in[0,1]$ is the inflation persistence or the relative weighting on historical inflation. ${ }^{2}$

\subsection{Consumption Good Firms}

While the intermediate-good firms operate in monopolistic competition, the consumptiongood firms face competitive markets for their output. Output $Y_{t}$ is determined by choosing an optimal combination of intermediate-good inputs $\left\{Y_{t}(f)\right\}$ in order to maximize profit $P_{t} Y_{t}-\int_{0}^{1} P_{t}(f) Y_{t}(f) d f$, subject to the technology constraint, $Y_{t}=\left(\int_{0}^{1} Y_{t}(f)^{\frac{\theta_{t}^{p}-1}{\theta_{t}^{p}}} d f\right)^{\frac{\theta_{t}^{p}}{\theta_{t}^{p}-1}}$.

Competitive markets in the consumption-good implies the consumption-good price is defined as $P_{t}=\left(\int_{0}^{1} P_{t}(f)^{1-\theta_{t}^{p}} d f\right)^{\frac{1}{1-\theta_{t}^{p}}}$. Then from the nominal rigidities arising form the Calvo price-setting in the intermediate-good firm sector, a New-Keynesian Phillips Curve variant is derived with inflation persistence, as shown in log-linear form (Kaihatsu and Kurozumi 2014)[pp.229-229,241] in the following:

$$
\hat{\pi}_{t}=\gamma_{p} \hat{\pi}_{t-1}+\beta\left(z^{*}\right)^{1-\sigma}\left(E_{t} \hat{\pi}_{t+1}-\gamma_{p} \hat{\pi}_{t}\right)+\frac{\left.\left(1-\xi_{p}\right)\left(1-\beta\left(z^{*}\right)^{1-\sigma} \xi_{p}\right)\right)}{\xi_{p}} \hat{m} c_{t}+z_{t}^{p}
$$

, where $z_{t}^{p}$ is an exogenous shock to the intermediate-good markup $\lambda_{t}^{p}$ (Kaihatsu and Kurozumi 2014)[p.231].

Then aggregating the production function over intermediate-good firms yields

$$
\hat{y}_{t}=(1+\phi)\left[(1-\alpha) \hat{h}_{t}+\alpha\left(\hat{u}_{t}+\hat{k}_{t-1}-z_{t}^{*}-z_{t}^{\psi}\right)\right]
$$

\subsection{Investment Good Firms}

The investment-good firms operate in a monopolistic market so that each firm $f_{i}$ has production technology that transforms one unit of consumption good into $\Psi_{t}$ units of the differenti-

\footnotetext{
${ }^{2}$ The re-optimization problem is explained in Kaihatsu and Kurozumi (2014)[pp.228-229]
} 
ated investment-good. In this context, $\Psi_{t}$ denotes the investment specific (IS) technology that is distinguished from the investment neutral technology in Kaihatsu and Kurozumi (2014), where $z_{t}^{\psi}$ is the non-stationary IS shock. and it is assumed to follow an $\operatorname{AR}(1)$ process given by

$$
\log \Psi_{t}=\log \Psi+\log \Psi_{t-1}+z_{t}^{\psi}
$$

The investment-good firm's cost minimization problem shows that real marginal costs equal the reciprocal of the IS technology level or $\frac{1}{\Psi_{t}}$ so that investment-good firms' marginal costs are identical. The monopolistically competitive investment-good firm, $f_{i}$, faces capitalgood firm demand given by $I_{t}\left(f_{i}\right)=I_{t}\left(\frac{P_{t}^{i}\left(f_{i}\right)}{P_{t}^{i}}\right)^{-\theta_{t}^{i}}$, where $P_{t}^{i}\left(f_{i}\right)$ is the investment-good price of firm $f_{i}$ and $I_{t}$ is an aggregate of differentiated investment goods. Following from the first order condition for investment-good firm profit maximization, Kaihatsu and Kurozumi (2014) [p.230] show that $I_{t}\left(f_{i}\right)=I_{t}$ or that price and output are symmetric in the investmentgood firm sector. In addition, the gross rate of change of the relative price of investment goods to consumption goods in

$$
r_{t}^{i}=\frac{\frac{P_{t}^{i}}{P_{t}}}{\frac{P_{t-1}^{i}}{P_{t-1}}}=\frac{1+\lambda_{t}^{i}}{1+\lambda_{t-1}^{i}} \frac{\Psi_{t-1}}{\Psi_{t}},
$$

where $\lambda_{t}^{i}=\frac{1}{\theta_{t}^{i}-1}>0$ is the investment-good markup over marginal cost $\frac{P_{t}}{\Psi_{t}}$. It should be noted that if the investment-good firms were in a competitive market, $\lambda^{i}=0$.

\subsection{Market Clearing for Consumption Goods}

The market clearing condition in log-linear form for consumption-goods, is standard version for a two sector economy with an additive exogenous shock to consumption good demand, $z_{t}^{g}$, namely,

$$
\hat{y}_{t}=\frac{c}{y} \hat{c}_{t}+\frac{i}{y} \hat{i}_{t}+z_{t}^{g} .
$$




\subsection{Capital Good Firms}

The discussion now turns to the evolution of capital in the Kaihatsu and Kurozumi (2014) model. Capital-goods firms buy capital goods $\left(1-\delta\left(u_{t}\right)\right) K_{t-1}$ from entrepreneurs and purchase a number of investment goods, thus making an investment. In addition to the presence of adjustment $\operatorname{costs} S\left(\frac{\frac{I_{t}}{I_{t-1}}}{\left(z^{*} \phi\right)}\right)$, a marginal efficiency of investment shock (MEI), $z^{v}$ is a feature of the model. The MEI shock affects the transformation of investment goods into capital goods and has been used in empirical studies such as Hirose and Kurozumi (2012) to explain much of the boom and bust cycle in Japan during the 1980's and 1990's. The linear law of motion for capital is thus

$$
\hat{k}_{t}=\frac{1-\delta-r^{E} \psi}{z^{*} \psi} \hat{u}_{t}+\frac{1-\delta}{z^{*} \psi}\left(\hat{k}_{t-1}-z_{t}^{*}-z_{t}^{\psi}\right)+\left(1-\frac{1-\delta}{z^{*} \psi}\right)\left(\hat{i}_{t}+z_{t}^{v}\right) .
$$

Subject to the capital evolution equation constraint, the capital-good firms choose investment to maximize profit according to the following objective function:

$$
\max _{I_{t}} \mathrm{E}_{0} \sum_{j=0}^{\infty} \beta^{j} \frac{\Lambda_{t+j}}{\Lambda_{t}}\left\{Q_{t+j}\left[K_{t+j}-\left(1-\delta\left(u_{t+j}\right) K_{t+j-1}\right]-\frac{P_{t+j}^{i}}{P_{t+j} I_{t+j}}\right\}\right.
$$

, yielding the first order condition,

$$
\hat{q}_{t}=\zeta\left(\hat{i}_{t}-\hat{i}_{t-1}+z_{t}^{*}+z_{t}^{\psi}\right)-\beta\left(z^{*}\right)^{1-\sigma} \zeta\left(E_{t} \hat{i}_{t+1}-\hat{i}_{t}+E_{t} z_{t+1}^{*}+E_{t} z_{t+1}^{\psi}\right)-z_{t}^{v}+z_{t}^{i}
$$

, where $z_{t}^{i}$ is an exogenous shock to the investment good markup $\lambda_{t}^{i}$ (Kaihatsu and Kurozumi 2014)[p.231]

\subsection{Central Bank}

The central bank sets the policy interest rate according to a Henderson-McKibbin Taylor (HMT) rule (Henderson and McKibbin 1993), (Taylor 1993), where $z_{t}^{r}$ is an exogenous monetary policy shock, given by

$$
\hat{r}_{t}^{n}=\phi_{r} \hat{r}_{t-1}^{n}+\left(1-\phi_{r}\right)\left(\frac{\phi_{\pi}}{4} \sum_{j=o}^{3} \hat{\pi}_{t-j}+\phi_{y} \hat{y}_{t}\right)+\phi_{\Delta y}\left(\hat{y}_{t}-\hat{y}_{t-1}+z_{t}^{*}\right)+z_{t}^{r} .
$$




\section{Empirical Results}

\subsection{Estimation Strategy}

\subsubsection{Baseline Model}

The baseline model used for the estimation is the Kaihatsu and Kurozumi (2014) DSGE model characterized by the equilibrium conditions in equations (1), (2), (4), (5), (6), (7), (8), (9), (12), (13), (14), (15), (18), (19), (20) and (21), together with the technology stochastic processes (neutral and IS) (11), (16) and the exogenous shocks, $z_{t}^{i}$, where $i \in$ $\{b, g, w, p, i, r, z, \psi, v, \mu, \eta\}, z_{t}^{i}=\rho_{i} z_{t-1}^{i}+\epsilon_{t}^{i}$ and $\epsilon_{t}^{i} \sim$ iid $N\left(0, \sigma_{i}^{2}\right)$. The baseline has the original monetary policy rule that does not respond to credit market factors, given by (21).

\subsubsection{Credit Market Factor Modified Model}

The objective of this paper is to assess whether there is evidence that the central bank, in particular the Federal Reserve, responds to credit market factors in setting its policy interest rate. Therefore, the specification of the monetary policy rule (21) is modified to incorporate responses to the external finance premium or credit spreads $\left(\phi_{e f p}\right)$, financial leverage $\left(\phi_{l}\right)$ and credit growth $\left(\phi_{c g}\right)$.

A comparison of model fit is made between various versions of the estimated DSGE model, modified for credit market factors and the baseline model, using Bayesian methods. Rather than estimating the policy rule parameters in isolation, a system-wide estimation approach is employed, which is compared with the baseline. As Lubik and Schorfheide (2007)[p.1074] argues, this has the advantage over single equation estimation as not only the policy parameters are estimated but so are the non-policy parameters and it permits the study of shock propagation and relative importance of shocks via impulse response and variance decomposition analysis. Hirose (2013)[p.3] argues there is the added benefit versus other some other approaches in that the estimation of DSGE models with Bayesian techniques, in the presence of cross-equation restrictions, avoids problems with misspecification and identification. 


\subsubsection{Bayesian Methodology}

The DSGE systems described above are expressed in variables which are log-linearized around a steady state and are de-trended for estimation so that $y_{t}=\frac{Y_{t}}{Z_{t}^{*}}, c_{t}=\frac{C_{t}}{Z_{t}^{*}}, w_{t}=\frac{W_{t}}{Z_{t}^{*}}$, $\lambda_{t}=\Lambda_{t}\left(Z_{t}^{*}\right)^{\sigma}, i_{t}=\frac{I_{t}}{\left(Z_{t}^{*} \Psi_{t}\right)}, r_{t}^{k}=R_{t}^{k} \Psi_{t}, n_{t}=\frac{N_{t}}{Z_{t}^{*}}$ and $l_{t}=\frac{L_{t}}{Z_{t}^{*}}$. The approach taken follows the Bayesian DSGE estimation literature such as Smets and Wouters (2007) and Kaihatsu and Kurozumi (2014).

A DSGE model can be described by the state space shown in the two equations below,

$$
y_{t}=A+B x_{t}
$$

and

$$
x_{t}=C(\theta) x_{t-1}+D(\theta) \epsilon_{t}
$$

,where $y_{t}$ is a vector of observables and $Y^{T}=\left\{y_{1}, \ldots, y_{T}\right\}$ and $\theta$ is a vector of model structural parameters. Equation (22) depicts the measurement equation which connects the model variables, $x_{t}$ to the observed data $y_{t}$, scaled by parameter matrices $\mathrm{A}$ and B. Equation (23) describes the transition equation for $x_{t}$, which relates to the (determinate) rational expectations equilibrium solution to the DSGE system. ${ }^{3}$

While assuming the shocks are normally distributed and with no serial correlation, the likelihood function is evaluated using a Kalman filter based on the state space form above, or

$$
\begin{aligned}
\mathscr{L}\left(\theta \mid Y^{T}\right) & =p\left(Y^{T} \mid \theta\right) \\
& =\prod_{t=1}^{T} p\left(y_{t} \mid Y^{t-1}, \theta\right) .
\end{aligned}
$$

The prior distribution density $p(\theta)$ assumptions for the parameters are made explicit shortly, which have a bounded domain reflecting a priori economic theory and convention. Combining the prior density with the Kalman filter evaluated likelihood function, by (24) yields the

\footnotetext{
${ }^{3}$ Indeterminacy and sunspot equilibria are not explicitly dealt with in this paper
} 
following:

$$
\begin{aligned}
p\left(Y^{T}, \theta\right) & =\mathscr{L}\left(\theta \mid Y^{T}\right) p(\theta) \\
& =p\left(Y^{T} \mid \theta\right) p(\theta) .
\end{aligned}
$$

Using Bayes theorem, the posterior distribution, $p\left(\theta \mid Y^{T}\right)$, is derived from (25) in the expression,

$$
p\left(\theta \mid Y^{T}\right)=\frac{p\left(Y^{T} \mid \theta\right) p(\theta)}{\int p\left(Y^{T} \mid \theta\right) p(\theta) d(\theta)} \propto \mathscr{L}\left(\theta \mid Y^{T}\right) p(\theta)
$$

, where $p(Y)=\int p\left(Y^{T} \mid \theta\right)$. The posterior first and second moments are computed numerically using draws from the Metropolis-Hastings algorithm, which is now described. ${ }^{4}$ Firstly, given the proportionality relationship in (26), maximizing the posterior distribution is equivalent to maximizing $\ln \mathscr{L}\left(\theta \mid Y^{T}\right)+\ln p(\theta)^{5}$, which is conducted using a numerical routine to find $\tilde{\theta}$, the mode of the posterior density and the inverse Hessian $\tilde{\Sigma}$ is computed at the mode.

The Random Walk Metropolis-Hastings algorithm begins with a draw $\theta^{(0)}$ from $N\left(\tilde{\theta}, c_{o}^{2} \tilde{\Sigma}\right)$ or a specification of an initial starting value. Then for simulations $s=1, \ldots, n_{\text {sim }}$, draw of a candidate parameter vector $v_{(i)}$ from a jumping distribution $J_{s}\left(v \mid \theta^{(s-1)}\right)$, where $J_{s} \sim$ $N\left(\theta^{(s-1)}, c^{2} \tilde{\Sigma}\right)$ and $c$ is the scale parameter. The jump from $\theta^{(s-1)}$ is accepted $\left(\theta^{(s)}=v\right)$ with probability $\min \left\{1, r\left(\theta^{(s-1)}, v \mid Y\right)\right\}$ and rejected $\left(\theta^{(s)}=\theta^{(s-1)}\right)$, otherwise. Note that $r\left(\theta^{(s-1)}, v \mid Y\right)=\frac{\mathscr{L}(v \mid Y) p(v)}{\mathscr{L}\left(\theta^{(s-1)} \mid Y\right) p\left(\theta^{(s-1)}\right)}$.

The posterior distribution is used to characterize the empirical results with respect to the parameters, $\theta$. The parameter point estimate is the posterior mean $\hat{\theta}$ in (27) and the dispersion of the parameter estimate is also given by the posterior distribution, described by probability (credible) intervals.

$$
\hat{\theta}=\int \theta p\left(\theta \mid Y^{T}\right) d \theta
$$

The first and second moments of $\theta^{(s)}$ are generated so as to numerically approximate

\footnotetext{
${ }^{4}$ The discussion closely follows An and Schorfheide (2007)

${ }^{5}$ Optimizers are preserved under positive monotonic transformations.
} 
the posterior point estimate in (27) and its variance. That is, by the weak law of large numbers, $E\left[\theta \mid Y^{T}\right]=\frac{1}{n s i m} \sum_{s=1}^{n s i m} \theta^{(s)} \stackrel{p}{\rightarrow} \int \theta p\left(\theta \mid Y^{T}\right) d \theta$ and $E\left[g(\theta) \mid Y^{T}\right]=\frac{1}{n s i m} \sum_{s=1}^{n s i m} g\left(\theta^{(s)}\right) \stackrel{p}{\rightarrow}$ $\int g(\theta) p\left(\theta \mid Y^{T}\right) d \theta$. The point estimates and the credible intervals around these estimates to follow in the empirical results section, are based on this methodology. In particular, since the core question is whether the central bank responds to credit market factors in a monetary policy rule, the point estimates and the probability intervals of estimated policy response parameters $\phi_{r}, \phi_{\pi}, \phi_{y}, \phi_{\Delta_{y}}, \phi_{e f p}, \phi_{l}$ and $\phi_{g}$ are germane to this empirical investigation.

Both the Kalman filter and the Metropolis-Hastings algorithm are performed using DYNARE (Adjemian, Bastani, Karame, Juillard, Maih, Mihoubi, Perendia, Pfeifeer, Ratto and Villemot 2014)[pp.48-67] so that empirical analysis can be undertaken. The number of simulations are set at $n$ sim $=200,000$ with the first half of the draws discarded and the scale parameter $c$ is chosen so that the acceptance ratio in the Metropolis-Hastings algorithm described above, is around 0.25 , which is consistent with the literature (Adjemian et al. 2014)[p.54].

The priors used in the baseline model remain unchanged from Kaihatsu and Kurozumi (2014) but three new policy parameters are introduced to reflect nominal interest rate response to credit market factors, namely, $\phi_{e f p}, \phi_{l}$ and $\phi_{g}$. Each has a domain on $\mathbb{R}$ and prior distributions are assumed to be Normal with a mean of 0 and a standard deviation of 1 . In the case of the estimate nominal interest rate response to the external finance premium, $\hat{\phi}_{e f p}<0$ would imply that the monetary authority is targeting credit spreads in monetary policy for stabilization purposes. When entrepreneurs are under stress from the rising cost of capital to finance investment, the central bank eases policy by lowering the policy interest rate. Conversely, when credit is easily available, the central bank raises rates which may temper potential inflationary outcomes. By setting the prior for $\phi_{\text {efp }}$ at $\mathrm{N}(0,1)$, the sign is not restricted so the data is left to answer the question of sign and the magnitude would reasonably be located around zero within a relatively tight band, so a standard deviation of one around the zero centred Normal distribution is chosen as a prior. In the case of the estimated monetary policy responses to financial leverage $\phi_{l}$ and $\phi_{c g}$, a positive point estimate would be considered evidence of policy targeting of these credit factors. A central bank raising the policy interest rate in the face of excessive financial leverage and credit growth would potentially be an effort to dampen inflationary pressures, while a reduction in rates, 
when leverage or credit growth is low, could be construed as an effort to stimulate demand as part of stabilization policy. Again, the choice here is not to constrain sign but to let the data determine the sign of these estimates and the expectation is that the magnitude would be relatively small centred around zero. Therefore a choice of $\mathrm{N}(0,1)$ as prior is made for these parameters.

In addition to the study of the point estimates is the issue of model fit. To be sure, the sign and significance of the parameter estimates of credit market factors in the monetary policy response function are important. However, this needs to be examined in the context of whether the inclusion of credit market factors in the monetary policy rule improve the fit of the model, for the data set concerned.

Relative fit is determined by a comparison of the log-marginal data density, evaluated at the posterior mode $(\tilde{\theta}$ and $\tilde{\Sigma})$ of the model that includes credit factors in the monetary policy rule, $\mathscr{M}_{1}$ and the baseline model, $\mathscr{M}_{2}$.

The marginal data density is defined as

$$
p\left(Y^{T} \mid M_{i}\right)=\int \mathscr{L}\left(\theta_{i} \mid Y^{T}, \mathscr{M}_{i}\right) p\left(\theta_{i} \mid \mathscr{M}_{i}\right) d \theta_{i}
$$

For computation of the log-marginal data density at the posterior mode $(\tilde{\theta}$ and $\tilde{\Sigma})$ a Laplace approximation is used to yield

$$
\ln \tilde{p}\left(Y^{T} \mid \mathscr{M}_{i}\right)=\frac{k}{2} \ln (2 \pi)+\ln p\left(\tilde{\theta} \mid Y^{T}, \mathscr{M}_{i}\right)+\ln p\left(\tilde{\theta} \mid \mathscr{M}_{i}\right)+\frac{1}{2} \ln |\tilde{\Sigma}| .
$$

The last term in (29), $\frac{1}{2} \ln |\tilde{\Sigma}| \approx-\frac{k}{2} \ln T$, is the Schwartz criterion (Schwartz 1978). Hence, the log-marginal data density may be interpreted as a log-likelihood function with a penalty for model dimensionality. ${ }^{6}$ Consequently, when evaluating models which include credit factors in the monetary policy rule, $\ln \tilde{p}\left(Y^{T} \mid \mathscr{M}_{1}\right)>\ln \tilde{p}\left(Y^{T} \mid \mathscr{M}_{2}\right)$ would be evidence that the inclusion of credit market factors in the monetary policy rule improves model fit. However, while this measure demonstrates whether one model is a better fit than another, it does not quantify the degree to which this is the case.

A posterior odds test is thus used to compare and quantify the relative fit of the baseline

\footnotetext{
${ }^{6}$ The log-marginal data density is computed using numerical methods in DYNARE.
} 
model versus the model that includes credit market factors in the monetary policy rule. Therefore, the posterior odds of $\mathscr{M}_{1}$ to $\mathscr{M}_{2}$ is given by

$$
\frac{\pi_{1, T}}{\pi_{2, T}}=\frac{\pi_{1,0}}{\pi_{2,0}} \frac{p\left(Y^{T} \mid \mathscr{M}_{1}\right)}{p\left(Y^{T} \mid \mathscr{M}_{2}\right.}
$$

The prior odds, $\frac{\pi_{1,0}}{\pi_{2,0}}$ are set to unity in this study so the posterior odds reduce to the Bayes Factor, $\frac{p\left(Y^{T} \mid \mathscr{M}_{1}\right)}{p\left(Y^{T} \mid \mathscr{M}_{2}\right.}$, which is the ratio of the model marginal densities, where Jeffreys Criterion (Jeffreys 1961) is used to determine the "strength of evidence" for model relative fit.

Of course, relative fit results are more compelling if the point estimates are of the correct sign and magnitude based on a priori theory and the probability intervals are supportive of the hypothesis.

\subsection{Data}

The sample period, the data sources and the observable equations match those in Kaihatsu and Kurozumi (2014)[p.231-232]. US quarterly data is used for empirical analysis. The sample period is $1985: 1 \mathrm{Q}$ to $2008: 4 \mathrm{Q}$, where the end date is judiciously chosen to avoid the zero lower bound, which has been sustained since 2009:1Q in the US. The macro aggregates are self explanatory but the choice of financial data is made explicit. The loan rate data used for the variable $E_{t}\left(r_{t+1}^{E} \pi_{t+1}\right)$ is the Moody's Baa corporate bond yield, so that the spread over the risk free rate or external finance premium is indeed a corporate credit spread measure. The data selection for the real loan variable, $L_{t}$ is total credit market borrowing of the non-financial business sector in the US Flow of Funds Statistics, deflated by the PCE price index, a proxy for the consumption-good price $P_{t}$. The data used for net worth $N_{t}$ is also sourced from the US Flow of Funds Statistics as a measure of "shareholders equity" or "total liabilities and equity" less "total liabilities" of the non-financial business sector, deflated by the PCE price index.

\subsection{Estimation Results}

The monetary policy rule in equation (21) is the baseline from the DSGE model described above. While it does include some lagged data terms, it contains the current period variables for both inflation and output and as such is a type of current data policy rule. In the upcoming 
discussion on robustness, some variants of this rule are considered, including a more forward looking expectations based version and a lagged data alternative is examined. In turn, the baseline policy rule is modified to include the three credit market factors being examined: the external finance premium, financial leverage and credit growth.

\subsubsection{External Finance Premium}

The baseline, current data monetary policy rule is modified to include an additive term, $e \hat{f} p_{t}=E_{t} \hat{r}_{t+1}^{E}-\left(\hat{r}_{t}^{n}-E_{t} \hat{\pi}_{t+1}\right)$ for the external finance premium, which represents the corporate real loan rate spread over the risk free real interest rate and is often described as measure of balance sheet stress, given by

$$
\hat{r}_{t}^{n}=\phi_{r} \hat{r}_{t-1}^{n}+\left(1-\phi_{r}\right)\left(\frac{\phi_{\pi}}{4} \sum_{j=o}^{3} \hat{\pi}_{t-j}+\phi_{y} \hat{y}_{t}\right)+\phi_{\Delta y}\left(\hat{y}_{t}-\hat{y}_{t-1}+z_{t}^{*}\right)+\phi_{e f p} e \hat{f} p_{t}+z_{t}^{r}
$$

If the central bank responds to credit spreads in setting its policy rate it will lower (raise) rates in response to an increase (decrease) in credit spreads so alleviate financial stress in the corporate sector during downturns and moderate inflation or inflationary expectations during upturns, as part of its macro-stabilization policy framework. Therefore, one would expect a central bank targeting the external finance premium to have $\hat{\phi}_{e f p}<0$ in the estimated policy rule.

In Table 1 and Table 2, the full set of estimated parameters (posterior distributions) and prior distributions of the DSGE model, previously outlined, are presented for the original policy rule (21) and the credit spread augmented version in (31), respectively. As previously stated, the beauty of the Bayesian DSGE estimation approach outlined, is that not only the policy parameters are estimated but the full macroeconomic model simultaneously.

The inclusion of the $\phi_{e f p}$ parameter does not meaningfully affect the estimates for the non-policy parameters as there is little difference between the results in the two tables. The choice of the Normal distribution prior is made so as to allow for sufficient degrees of freedom for the data to dictate the sign of $\phi_{e f p}$ and estimate the DSGE system as a whole rather than choosing a prior that would be tantamount to imposing a sign restriction, which may affect the integrity of the non-policy parameter set. 


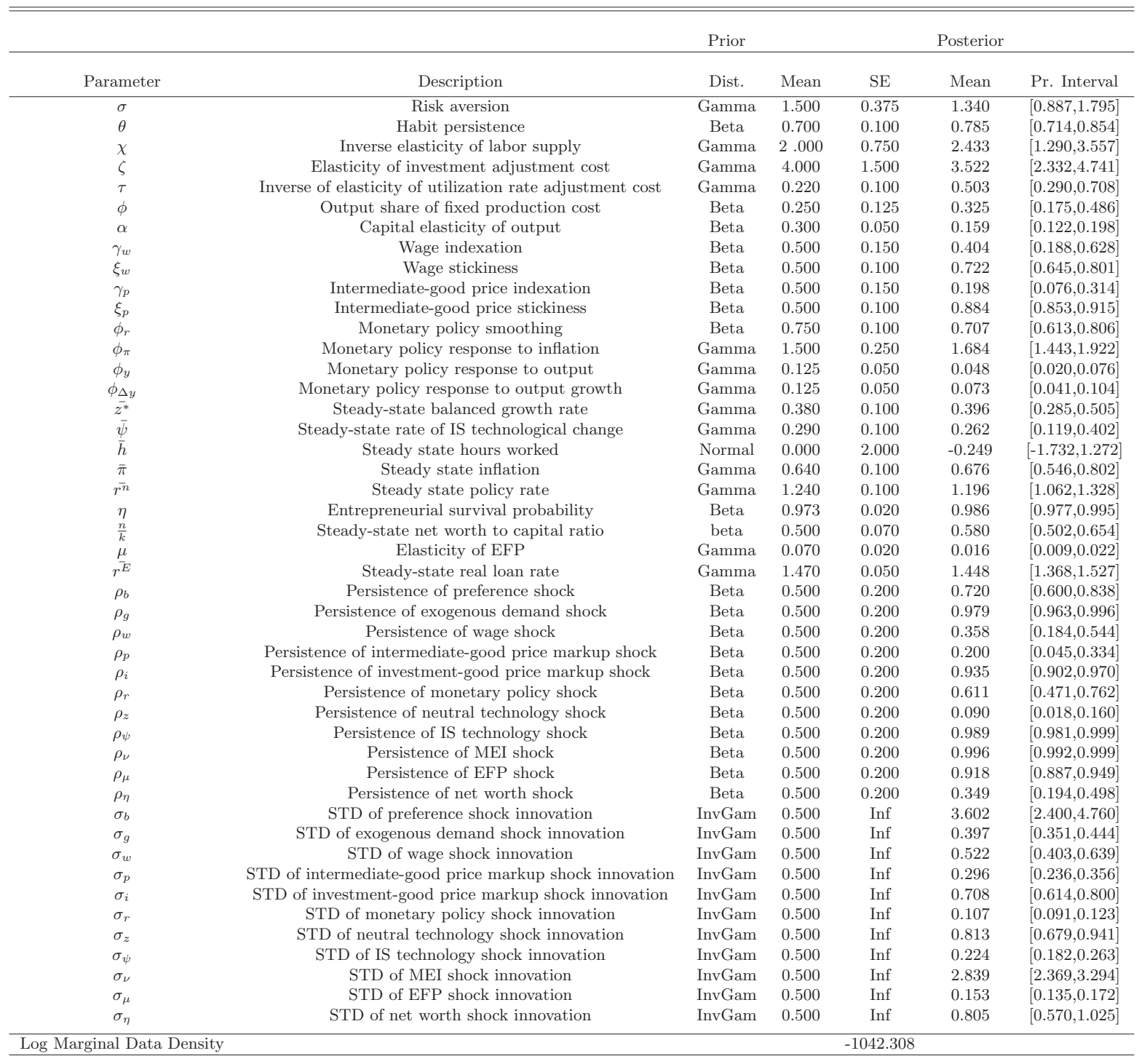

Table 1: Baseline Original Model - Prior and Posterior Distributions 


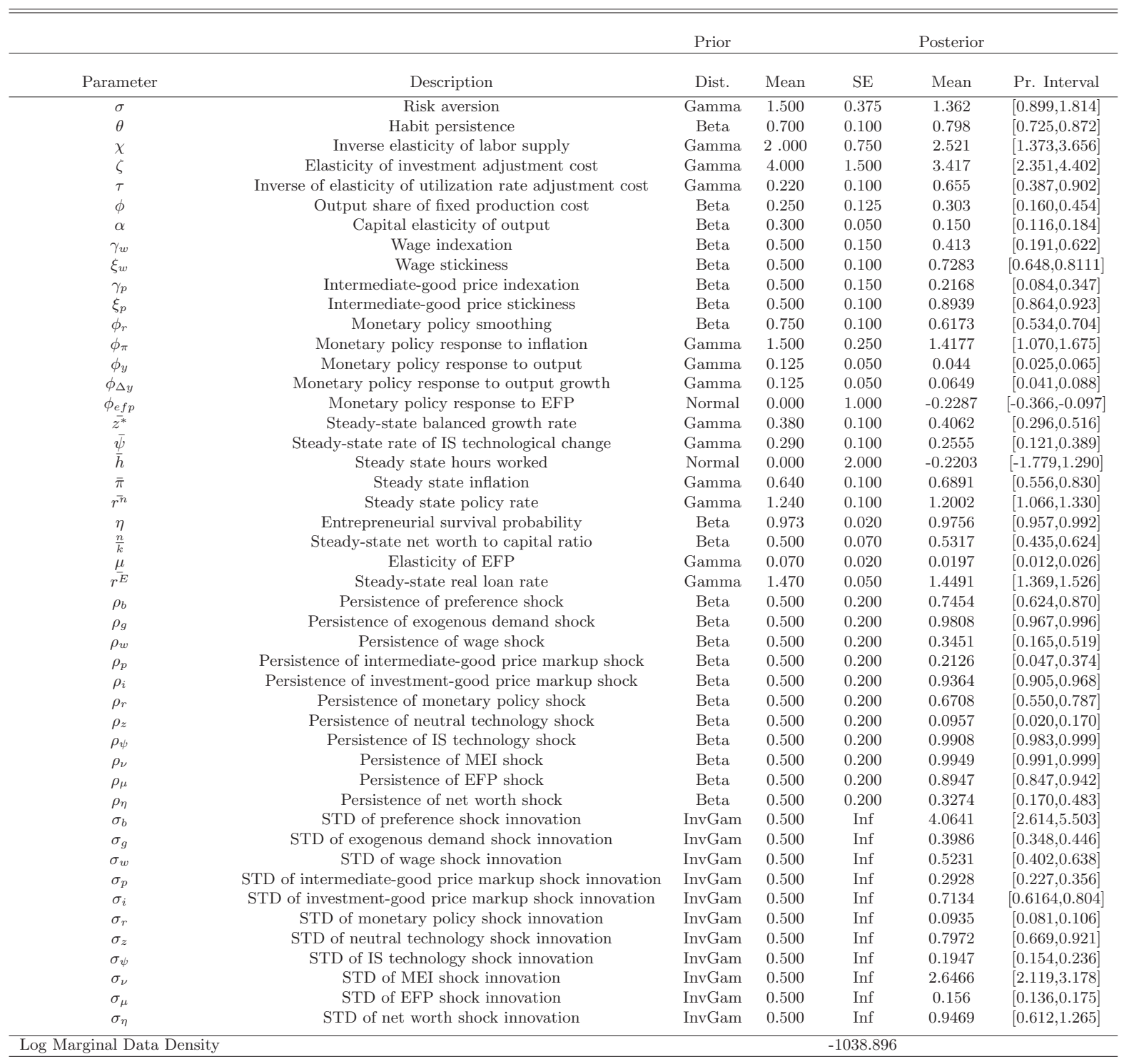

Table 2: EFP Augmented Policy Rule in Original Model - Prior and Posterior Distributions

The policy related results are summarized in Table 3. Following the notation from the Bayesian Methodology section, let $\mathscr{M}_{1}$ denote the model with the external finance premium augmented policy rule in 31 and $\mathscr{M}_{2}$ denote the original baseline model. Regarding the comparison with the point estimates of the baseline $\mathscr{M}_{2}$, the inclusion of $\hat{\phi}_{\text {efp }}$ in $\mathscr{M}_{1}$ as a policy response parameter, has reduced the degree of policy smoothing as the posterior mean of $\hat{\phi}_{r}$ has fallen from 0.707 to 0.617 . Also, the response to inflation has diminished as the posterior point estimate has fallen from 1.684 to 1.418. 
More significant is that the estimated parameter is negative, $\hat{\phi}_{\text {efp }}<0$ and encouragingly the full range of the 90 percent probability interval $[-0.366,-0.097]$ is below zero and this is supported by the log-marginal data density rising from -1042.308 to -1038.896 with the inclusion of this estimated parameter. Furthermore, the posterior odds test statistic (Bayes Factor) is 30.326, which based on the Jeffreys (1961) criterion for strength of evidence is "very strong". Consequently, there is a compelling evidence that the central bank does indeed respond to credit spreads in setting the policy interest rate.

\begin{tabular}{|c|c|c|c|c|c|c|}
\hline \multirow[b]{2}{*}{ Parameter } & \multirow[b]{2}{*}{ Domain } & \multirow[b]{2}{*}{ Density } & \multicolumn{2}{|c|}{$\begin{array}{c}\mathscr{M}_{1} \\
\text { EFP in Policy Rule } \\
\left|\phi_{\text {efp }}\right|>0\end{array}$} & \multicolumn{2}{|c|}{$\begin{array}{c}\mathscr{M}_{2} \\
\text { Baseline Policy Rule } \\
\phi_{\text {efp }}=0\end{array}$} \\
\hline & & & Post. Mean & Prob.Interval & Post. Mean & Prob.Interval \\
\hline$\phi_{r}$ & {$[0,1)$} & Beta & 0.617 & {$[0.534,0.704]$} & 0.707 & {$[0.613,0.806]$} \\
\hline$\phi_{\pi}$ & $\mathbb{R}^{+}$ & Gamma & 1.418 & {$[1.070,1.675]$} & 1.684 & {$[1.443,1.922]$} \\
\hline$\phi_{y}$ & $\mathbb{R}^{+}$ & Gamma & 0.044 & {$[0.025,0.065]$} & 0.048 & {$[0.020,0.076]$} \\
\hline$\phi_{\Delta y}$ & $\mathbb{R}^{+}$ & Gamma & 0.065 & {$[0.041,0.088]$} & 0.073 & {$[0.041,0.104]$} \\
\hline$\phi_{e f p}$ & $\mathbb{R}$ & Normal & -0.229 & {$[-0.366,-0.097]$} & & \\
\hline Log Data Density & & & -1038.896 & & -1042.308 & \\
\hline Posterior Odds $\left(\pi_{1, T} / \pi_{2, T}\right)$ & & & 30.326 & & & \\
\hline
\end{tabular}

Table 3: Policy Response to the EFP - Parameter Estimates and Posterior Odds

There is some intuition behind this result. In the baseline model, the responses from $\phi_{y}$ and $\phi_{\Delta y}$ are minor. The main features are evidence of the Taylor Principle (Taylor 1993) or $\phi_{\pi}>1$ and significant policy smoothing $\phi_{r}=0.707$, both of which are well known in the literature for macro stabilization benefits. The inclusion of $\phi_{e f p}$ in the policy rule reduces the importance of $\phi_{\pi}$ and $\phi_{r}$ but does not vitiate the Taylor Principle or the importance of policy smoothing. It does suggest that a signal is given by credit spreads, that may offer information regarding future inflation or stress at the firm that is not picked up by output, output change or the inflation rate. As Gilchrist and Zakrajsek (2011) argue, the predictive component of corporate bond spreads reflects the ability of the bond market to signal conditions at the firm via cash flows more accurately than other indicators. Given that the central bank is rational and knows the structure of the model, then it follows that the monetary policy rule responds inversely to the credit spreads since it provides a predictive forward looking signal that is shown empirically in the impulse response section herein, via the credit channel in the structural model, to have macro stabilization merit. This is indeed borne out by the data. 


\subsubsection{Financial Leverage}

The financial leverage augmented, current data policy rule is the following,

$$
\hat{r}_{t}^{n}=\phi_{r} \hat{r}_{t-1}^{n}+\left(1-\phi_{r}\right)\left(\frac{\phi_{\pi}}{4} \sum_{j=o}^{3} \hat{\pi}_{t-j}+\phi_{y} \hat{y}_{t}\right)+\phi_{\Delta y}\left(\hat{y}_{t}-\hat{y}_{t-1}+z_{t}^{*}\right)+\phi_{l} \hat{l}_{t}+z_{t}^{r} .
$$

The economy-wide total real loan amount or $L_{t}=Q_{t} K_{t}-N_{t}$ represents the amount of credit outstanding in the economy and is a measure of financial leverage. This is an indicator of financial risk and it has been advocated in the literature by Curdia and Woodford (2010), among others, as a response variable in monetary policy rules. If a monetary authority is responding to financial leverage for macro stabilization then the policy response in the financial leverage augmented policy rule in (32) should have the following sign, $\phi_{l}>0$. If the economy is weak and demand for loans is low then the central bank would lower rates to increase the demand for loans for purchasing capital and stimulating investment and output. Conversely, if financial leverage is high, it could be indicative of higher expected inflation (or possible financial bubbles) and a policy to raise rates should dampen inflation as part of the macro stabilization policy. 


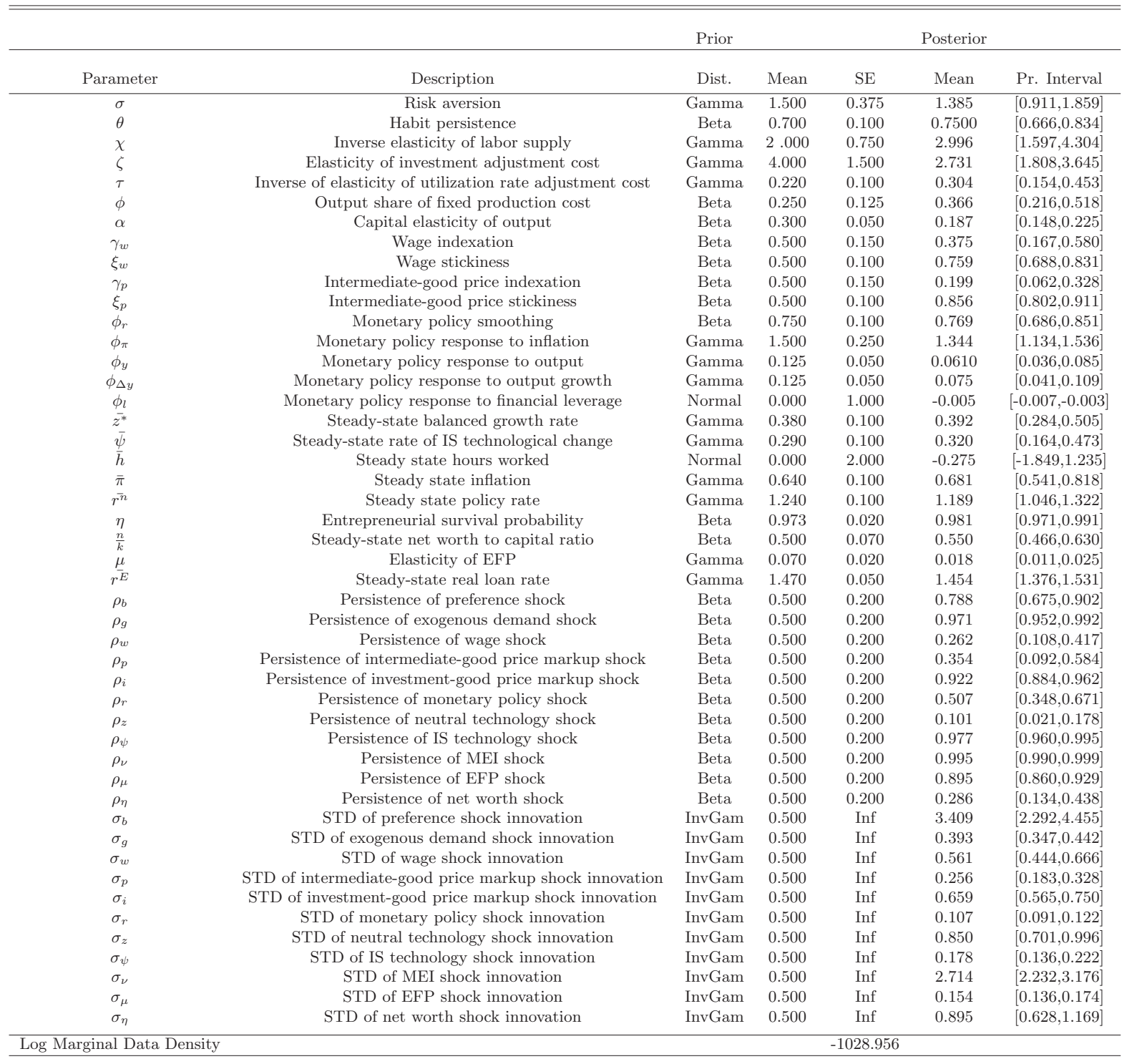

Table 4: Financial Leverage Augmented Policy Rule in Original Model - Prior and Posterior Distributions 


\begin{tabular}{|c|c|c|c|c|c|c|}
\hline \multirow[b]{2}{*}{ Parameter } & \multirow[b]{2}{*}{ Domain } & \multirow[b]{2}{*}{ Density } & \multicolumn{2}{|c|}{$\begin{array}{c}\mathscr{M}_{1} \\
\text { Leverage in Policy Rule } \\
\left|\phi_{l}\right|>0\end{array}$} & \multicolumn{2}{|c|}{$\begin{array}{c}\mathscr{M}_{2} \\
\text { Baseline Policy Rule } \\
\phi_{l}=0\end{array}$} \\
\hline & & & Post. Mean & Prob.Interval & Post. Mean & Prob.Interval \\
\hline$\phi_{r}$ & {$[0,1)$} & Beta & 0.769 & {$[0.686,0.851]$} & 0.707 & {$[0.613,0.806]$} \\
\hline$\phi_{\pi}$ & $\mathbb{R}^{+}$ & Gamma & 1.344 & {$[1.134,1.536]$} & 1.684 & {$[1.443,1.922]$} \\
\hline$\phi_{y}$ & $\mathbb{R}^{+}$ & Gamma & 0.061 & {$[0.036,0.085]$} & 0.048 & {$[0.020,0.076]$} \\
\hline$\phi_{\Delta y}$ & $\mathbb{R}^{+}$ & Gamma & 0.075 & {$[0.041,0.109]$} & 0.073 & {$[0.041,0.104]$} \\
\hline$\phi_{l}$ & $\mathbb{R}$ & Normal & -0.005 & {$[-0.007,-0.003]$} & & \\
\hline Log Data Density & & & -1028.956 & & -1042.308 & \\
\hline Posterior Odds $\left(\pi_{1, T} / \pi_{2, T}\right)$ & & & $6.29 \times 10^{5}$ & & & \\
\hline
\end{tabular}

Table 5: Policy Response to Financial Leverage - Parameter Estimates and Posterior Odds

Consider Table 5, which contains a summary of the policy parameter prior distributions and posterior point estimates for the comparison of original model modified to include financial leverage, $\mathscr{M}_{1}$ and the baseline, $\mathscr{M}_{2}$. Firstly, the inclusion of financial leverage in the policy rule lowers the estimated response parameter on inflation $\phi_{\pi}$ from 1.684 to 1.344 but the Taylor Principle is maintained. Unlike the case of the inclusion of $\phi_{e f p}$, the inclusion of $\phi_{l}$ raises $\phi_{r}$. Again, there is little change to $\phi_{y}$ and $\phi_{\Delta y}$.

The main parameter of interest in this case is the policy response to financial leverage $\phi_{l}$, which is negative and is not what one would expect from a central bank if it is targeting financial leverage in a stabilization context. The magnitude is near zero but the probability interval $[-0.007,-0.003]$ is clearly negative. The relative fit of $\mathscr{M}_{1}$ is very good indeed. The $\log$ data density is -1028.956 , which is greater than the -1042.308 in the baseline $\mathscr{M}_{2}$ and the posterior odds statistic is significantly greater than 100 so according to the Jeffrey's Criterion the strength of evidence test is "decisive".

There is no doubt that the fit of the model with financial leverage is superior to the baseline but the interpretation is not one consistent with a macro stabilization oriented monetary policy rule, for the reasons outlined. However, there is an interpretation. If there is a consistent negative (positive) response to the policy rate in the face of rising (falling) credit levels in the economy, then a conclusion is the monetary authority is acting pro-cyclically with respect to financial leverage in the economy. That is, when bank credit levels are high, the central bank is lowering the policy rate, encouraging more lending, which fuels more credit, possibly contributing to speculative bubbles. Alternatively, when bank credit levels 
are low, nominal rates rise, discouraging loans, which may lead to a lower level of credit and possibly recession. The results with respect to credit indicate the central bank is promoting persistence and not macro stabilization.

\subsubsection{Credit Growth}

The credit growth augmented current data policy rule is given by:

$$
\hat{r}_{t}^{n}=\phi_{r} \hat{r}_{t-1}^{n}+\left(1-\phi_{r}\right)\left(\frac{\phi_{\pi}}{4} \sum_{j=o}^{3} \hat{\pi}_{t-j}+\phi_{y} \hat{y}_{t}\right)+\phi_{\Delta y}\left(\hat{y}_{t}-\hat{y}_{t-1}+z_{t}^{*}\right)+\phi_{g} \hat{g}_{t}+z_{t}^{r},
$$

where credit growth is defined as $\hat{g}_{t}=l_{t}-l_{t-1}+z_{t}^{*}$, the change in real loans adjusted for the balanced growth rate.

Credit growth is the final variable added to the original baseline monetary policy rule in (33) with a response parameter $\phi_{g}$. In a similar fashion to financial leverage, if a central bank is targeting credit growth as a variable in a monetary policy rule for stabilization purposes, then the sign should be $\phi_{g}>0$. As when the absolute level of credit is high, if the growth is high then an anti-inflationary stance would be to raise rates and similarly anti-recessionary policy to lower rates when credit growth is low or negative. 


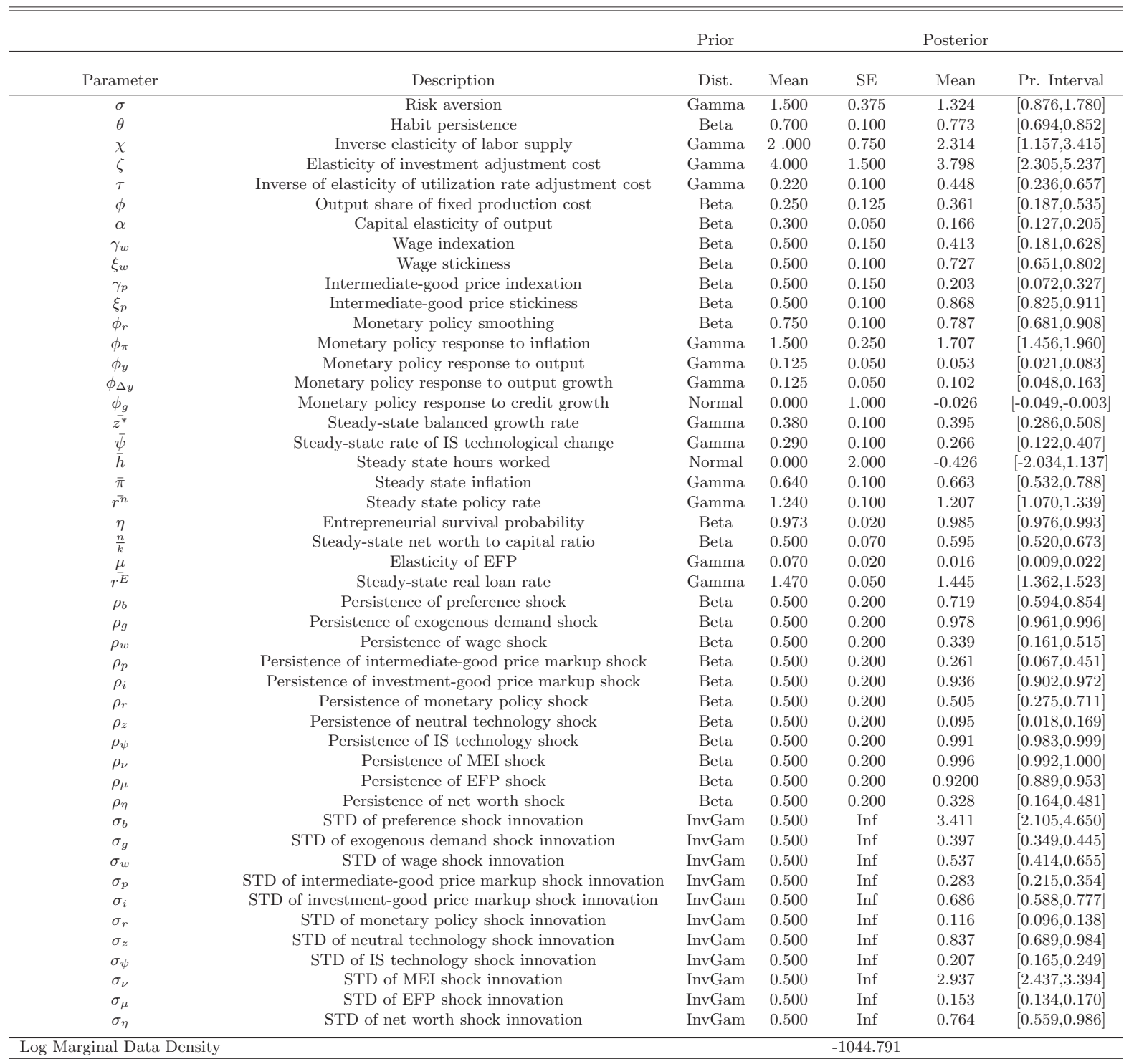

Table 6: Credit Growth Augmented Policy Rule in Original Model - Prior and Posterior Distributions 


\begin{tabular}{|c|c|c|c|c|c|c|}
\hline \multirow[b]{2}{*}{ Parameter } & \multirow[b]{2}{*}{ Domain } & \multirow[b]{2}{*}{ Density } & \multicolumn{2}{|c|}{$\begin{array}{c}\mathscr{M}_{1} \\
\text { Credit Growth in Policy Rule } \\
\left|\phi_{g}\right|>0\end{array}$} & \multicolumn{2}{|c|}{$\begin{array}{c}\mathscr{M}_{2} \\
\text { Baseline Policy Rule } \\
\phi_{g}=0\end{array}$} \\
\hline & & & Post. Mean & Prob.Interval & Post. Mean & Prob.Interval \\
\hline$\phi_{r}$ & {$[0,1)$} & Beta & 0.787 & {$[0.681,0.0 .908]$} & 0.707 & {$[0.613,0.806]$} \\
\hline$\phi_{\pi}$ & $\mathbb{R}^{+}$ & Gamma & 1.707 & {$[1.456,1.960]$} & 1.684 & {$[1.443,1.922]$} \\
\hline$\phi_{y}$ & $\mathbb{R}^{+}$ & Gamma & 0.053 & {$[0.021,0.083]$} & 0.048 & {$[0.020,0.076]$} \\
\hline$\phi_{\Delta y}$ & $\mathbb{R}^{+}$ & Gamma & 0.102 & {$[0.048,0.163]$} & 0.073 & {$[0.041,0.104]$} \\
\hline$\phi_{g}$ & $\mathbb{R}$ & Normal & -0.026 & {$[-0.049,-0.003]$} & & \\
\hline Log Data Density & & & -1044.791 & & -1042.308 & \\
\hline Posterior Odds $\left(\pi_{1, T} / \pi_{2, T}\right)$ & & & 0.083 & & & \\
\hline
\end{tabular}

Table 7: Policy Response to Credit Growth - Parameter Estimates and Posterior Odds

The results in Table 7 do not support the hypothesis that the central bank responds to credit growth and, in fact, this credit market factor is the least compelling of the three factors considered. Firstly, $\phi_{r}, \phi_{1}$ and $\phi_{\Delta y}$ increase with the inclusion of the credit growth variable in the policy rule. Then the sign on $\phi_{g}<0$, is not desired from a policy perspective and finally the relative fit is poor. The log data density is -1044.791 for the model with credit growth, $\mathscr{M}_{1}$, which is less than that of the baseline, $\mathscr{M}_{2}$, at -1042.308 . The resulting posterior odds score of 0.083 is rated "Negative" on the Jeffrey's criterion. It is therefore conclusive that the central bank does not respond to credit growth in setting the policy interest rate. 


\subsection{Robustness Analysis}

Two variations of the baseline monetary policy rule (21) are employed to assess the robustness of the results in the previous section. The first is a forward looking policy rule, which replaces the current inflation and output terms $\pi_{t}$ and $y_{t}$ in (21) with their one step ahead expectation counterparts, $E_{t} \pi_{t+1}$ and $E_{t} y_{t+1}$, respectively in,

$$
\hat{r}_{t}^{n}=\phi_{r} \hat{r}_{t-1}^{n}+\left(1-\phi_{r}\right)\left(\frac{\phi_{\pi}}{4}\left(\sum_{j=1}^{3} \hat{\pi}_{t-j}+E_{t} \hat{\pi}_{t+1}\right)+\phi_{y} E_{t} \hat{y}_{t+1}\right)+\phi_{\Delta y}\left(\hat{y}_{t}-\hat{y}_{t-1}+z_{t}^{*}\right)+z_{t}^{r} .
$$

The second variation is a lagged-data variant of the original policy rule, which replaces current output, $y_{t}$ in (21) with lagged output $y_{t-1}$ and leaves inflation terms unchanged as inflation already appears in both a current and lagged data form. Therefore, the lagged data policy rule baseline is provided in

$$
\hat{r}_{t}^{n}=\phi_{r} \hat{r}_{t-1}^{n}+\left(1-\phi_{r}\right)\left(\frac{\phi_{\pi}}{4} \sum_{j=o}^{3} \hat{\pi}_{t-j}+\phi_{y} \hat{y}_{t-1}\right)+\phi_{\Delta y}\left(\hat{y}_{t}-\hat{y}_{t-1}+z_{t}^{*}\right)+z_{t}^{r} .
$$

\subsubsection{Rule Variations and the External Finance Premium}

The results from the original monetary policy rule, adjusted for the external finance premium, showed strong evidence that the central bank responded to credit spreads, with posterior

estimate $\hat{\phi}_{\text {efp }}$ sign and magnitude, together with model fit supportive of this conclusion. In order to assess the conviction of this conclusion, the forward rule and a lagged data rules are examined in turn to determine whether the initial promising results are robust to variants of the policy rule.

The first policy rule variation considered is the forward-looking expectations rule with the baseline (34) and the external finance premium modified counterpart (36). 


$$
\begin{array}{r}
\hat{r}_{t}^{n}=\phi_{r} \hat{r}_{t-1}^{n}+\left(1-\phi_{r}\right)\left(\frac{\phi_{\pi}}{4}\left(\sum_{j=1}^{3} \hat{\pi}_{t-j}+E_{t} \hat{\pi}_{t+1}\right)+\phi_{y} E_{t} \hat{y}_{t+1}\right)+\phi_{\Delta y}\left(\hat{y}_{t}-\hat{y}_{t-1}+z_{t}^{*}\right) \\
+\phi_{\text {efp }} e \hat{f} p+z_{t}^{r}
\end{array}
$$

\begin{tabular}{|c|c|c|c|c|c|c|}
\hline \multirow[b]{2}{*}{ Parameter } & \multirow[b]{2}{*}{ Domain } & \multirow[b]{2}{*}{ Density } & \multicolumn{2}{|c|}{$\begin{array}{c}\mathscr{M}_{1} \\
\text { EFP in Policy Rule } \\
\left|\phi_{\text {efp }}\right|>0\end{array}$} & \multicolumn{2}{|c|}{$\begin{array}{c}\mathscr{M}_{2} \\
\text { Baseline Policy Rule } \\
\phi_{\text {efp }}=0\end{array}$} \\
\hline & & & Post. Mean & Prob.Interval & Post. Mean & Prob.Interval \\
\hline$\phi_{r}$ & {$[0,1)$} & Beta & 0.555 & {$[0.450,0.651]$} & 0.719 & {$[0.599,0.845]$} \\
\hline$\phi_{\pi}$ & $\mathbb{R}^{+}$ & Gamma & 1.243 & {$[0.995,1.540]$} & 1.622 & {$[1.397,1.866]$} \\
\hline$\phi_{y}$ & $\mathbb{R}^{+}$ & Gamma & 0.046 & {$[0.021,0.071]$} & 0.047 & {$[0.016,0.077]$} \\
\hline$\phi_{\Delta y}$ & $\mathbb{R}^{+}$ & Gamma & 0.051 & {$[0.032,0.071]$} & 0.083 & {$[0.035,0.142]$} \\
\hline$\phi_{e f p}$ & $\mathbb{R}$ & Normal & -0.373 & {$[-0.556,-0.208]$} & & \\
\hline Log Data Density & & & -1037.422 & & -1043.853 & \\
\hline Posterior Odds $\left(\pi_{1, T} / \pi_{2, T}\right)$ & & & 620.794 & & & \\
\hline
\end{tabular}

Table 8: EFP Response to Expectational Policy Rule Variation - Parameter Estimates and Posterior Odds

Following the convention from the methodology section, the new baseline is labelled as $\mathscr{M}_{2}$ and the alternative $\mathscr{M}_{1}$. The inclusion of the external finance premium in $\mathscr{M}_{1}$ corresponds with a fall relative to baseline in the magnitude of all other estimated parameters. The posterior mean for $\phi_{r}$ drops from 0.719 to $0.555, \phi_{\pi}$ from 1.6222 to 1.243 and there are marginal declines in $\phi_{y}$ and $\phi_{\Delta y}$. Again, the credit spread response parameter $\phi_{e f p}$ is negative but the magnitude -0.373 versus -0.229 in the original baseline, with the probability interval $[-0.556,-0.208]$ more negative than the original baseline. The point estimate and the credible interval suggest a stronger negative response to credit spreads in this policy rule. The magnitude of the parameter estimate is particularly impressive since the standard deviation chosen for the Normal distribution prior was unity and thus not a large variance on the prior. The log-data density for the credit spread adjusted policy rule is greater than the baseline and the posterior odds ratio is 620.794 which indicates the relative fit of $\mathscr{M}_{1}$ over $\mathscr{M}_{2}$ is "decisive", by the Jeffrey's Criterion for posterior odds tests. Therefore, the conclusion that the central bank responded to credit spread using the current data policy rule is robust 
to the expectations version of that rule.

The lagged data rule, amended for the external finance premium, is

$$
\hat{r}_{t}^{n}=\phi_{r} \hat{r}_{t-1}^{n}+\left(1-\phi_{r}\right)\left(\frac{\phi_{\pi}}{4} \sum_{j=o}^{3} \hat{\pi}_{t-j}+\phi_{y} \hat{y}_{t-1}\right)+\phi_{\Delta y}\left(\hat{y}_{t}-\hat{y}_{t-1}+z_{t}^{*}\right)+\phi_{e f p} e \hat{f} p+z_{t}^{r}
$$

and its baseline counterpart is presented in (35).

\begin{tabular}{|c|c|c|c|c|c|c|}
\hline \multirow[b]{2}{*}{ Parameter } & \multirow[b]{2}{*}{ Domain } & \multirow[b]{2}{*}{ Density } & \multicolumn{2}{|c|}{$\begin{array}{c}\mathscr{M}_{1} \\
\text { EFP in Policy Rule } \\
\left|\phi_{\text {efp }}\right|>0\end{array}$} & \multicolumn{2}{|c|}{$\begin{array}{c}\mathscr{M}_{2} \\
\text { Baseline Policy Rule } \\
\phi_{\text {efp }}=0\end{array}$} \\
\hline & & & Post. Mean & Prob.Interval & Post. Mean & Prob.Interval \\
\hline$\phi_{r}$ & {$[0,1)$} & Beta & 0.644 & {$[0.559,0.727]$} & 0.753 & {$[0.661,0.853]$} \\
\hline$\phi_{\pi}$ & $\mathbb{R}^{+}$ & Gamma & 1.474 & {$[1.063,1.738]$} & 1.703 & {$[1.457,1.946]$} \\
\hline$\phi_{y}$ & $\mathbb{R}^{+}$ & Gamma & 0.030 & {$[0.013,0.047]$} & 0.030 & {$[0.010,0.048]$} \\
\hline$\phi_{\Delta y}$ & $\mathbb{R}^{+}$ & Gamma & 0.066 & {$[0.040,0.090]$} & 0.087 & {$[0.041,0.137]$} \\
\hline$\phi_{e f p}$ & $\mathbb{R}$ & Normal & -0.216 & {$[-0.344,-0.096]$} & & \\
\hline Log Data Density & & & -1042.879 & & -1045.218 & \\
\hline Posterior Odds $\left(\pi_{1, T} / \pi_{2, T}\right)$ & & & 10.361 & & & \\
\hline
\end{tabular}

Table 9: EFP Response to Lagged Policy Rule Variation - Parameter Estimates and Posterior Odds

In Table 9 it is clear that the inclusion of the external finance premium in the baseline policy rule implies that the posterior point estimates for each non-credit market factor are lower than baseline as with the forward looking and current data policy rules. The sign of the $\phi_{\text {efp }}$ is again negative at -0.216 but the magnitude is not as high as for the current data and expectational policy rules. Yet the probability interval for $\phi_{e f p}$ is fully below zero on the real line, which is supportive of a negative sign on this parameter estimate. Furthermore, the relative fit of $\mathscr{M}_{1}$ is good with a log data density of -1042.879 , which is greater than the baseline at -1045.218. Finally, the Posterior odds of $\mathscr{M}_{1}$ over $\mathscr{M}_{2}$ is 10.361 , which is "Strong", based on the Jeffrey's Criterion. This favours the relative fit of the model which contains the credit spread augmented policy rule. Again, the results supports the conclusion that the central bank responded to the external finance premium, for the time period tested.

Therefore, the question of whether the monetary authority responds to credit spreads or the external finance premium in the DSGE model containing the current data policy rule is robust to models including forward looking and lagged data rules. 


\subsubsection{Rule Variations and Financial Leverage}

The forward looking policy rule, amended to include a financial leverage term, is stated as

$$
\begin{array}{r}
\hat{r}_{t}^{n}=\phi_{r} \hat{r}_{t-1}^{n}+\left(1-\phi_{r}\right)\left(\frac{\phi_{\pi}}{4}\left(\sum_{j=1}^{3} \hat{\pi}_{t-j}+E_{t} \hat{\pi}_{t+1}\right)+\phi_{y} E_{t} \hat{y}_{t+1}\right)+\phi_{\Delta y}\left(\hat{y}_{t}-\hat{y}_{t-1}+z_{t}^{*}\right) \\
+\phi_{l} \hat{l}_{t}+z_{t}^{r},
\end{array}
$$

\begin{tabular}{|c|c|c|c|c|c|c|}
\hline \multirow[b]{2}{*}{ Parameter } & \multirow[b]{2}{*}{ Domain } & \multirow[b]{2}{*}{ Density } & \multicolumn{2}{|c|}{$\begin{array}{c}\mathscr{M}_{1} \\
\text { EFP in Policy Rule } \\
\left|\phi_{l}\right|>0\end{array}$} & \multicolumn{2}{|c|}{$\begin{array}{c}\mathscr{M}_{2} \\
\text { Baseline Policy Rule } \\
\phi_{l}=0\end{array}$} \\
\hline & & & Post. Mean & Prob.Interval & Post. Mean & Prob.Interval \\
\hline$\phi_{r}$ & {$[0,1)$} & Beta & 0.746 & {$[0.656,0.841]$} & 0.719 & {$[0.599,0.845]$} \\
\hline$\phi_{\pi}$ & $\mathbb{R}^{+}$ & Gamma & 1.312 & {$[1.125,1.496]$} & 1.622 & {$[1.397,1.866]$} \\
\hline$\phi_{y}$ & $\mathbb{R}^{+}$ & Gamma & 0.066 & {$[0.040,0.090]$} & 0.047 & {$[0.016,0.077]$} \\
\hline$\phi_{\Delta y}$ & $\mathbb{R}^{+}$ & Gamma & 0.064 & {$[0.032,0.095]$} & 0.083 & {$[0.035,0.142]$} \\
\hline$\phi_{l}$ & $\mathbb{R}$ & Normal & -0.006 & {$[-0.009,-0.003]$} & & \\
\hline Log Data Density & & & -1027.297 & & -1043.853 & \\
\hline Posterior Odds $\left(\pi_{1, T} / \pi_{2, T}\right)$ & & & $15.495 \times 10^{6}$ & & & \\
\hline
\end{tabular}

with the appropriate baseline in equation (34).

Table 10: Financial leverage Response to Forward Looking Policy Rule Variation - Parameter Estimates and Posterior Odds

The relevant feature is the continued negative sign on the financial leverage response parameter $\phi_{l}$ with the probability interval again fully negative at $[-0.009,-0.003]$ and the extremely good fit with the Posterior odds clearly in the "Decisive" rating zone based on the Jeffreys Criterion. Hence, the conclusion under the forward looking rule is the same as the current data rule, namely, the nominal interest rate does respond to financial leverage but pro-cyclically and not as part of a stabilization policy.

The lagged data rule, augmented to include a policy response to financial leverage, is stated as

$$
\hat{r}_{t}^{n}=\phi_{r} \hat{r}_{t-1}^{n}+\left(1-\phi_{r}\right)\left(\frac{\phi_{\pi}}{4} \sum_{j=o}^{3} \hat{\pi}_{t-j}+\phi_{y} \hat{y}_{t-1}\right)+\phi_{\Delta y}\left(\hat{y}_{t}-\hat{y}_{t-1}+z_{t}^{*}\right)+\phi_{l} \hat{l}_{t}+z_{t}^{r}
$$

with the baseline counterpart represented by equation (35)

Again for the lagged data rule, $\phi_{l}<0$ and the relative fit is "Decisive" by the Jeffrey's 


\begin{tabular}{|c|c|c|c|c|c|c|}
\hline \multirow[b]{2}{*}{ Parameter } & \multirow[b]{2}{*}{ Domain } & \multirow[b]{2}{*}{ Density } & \multicolumn{2}{|c|}{$\begin{array}{c}\mathscr{M}_{1} \\
\text { EFP in Policy Rule } \\
\left|\phi_{l}\right|>0\end{array}$} & \multicolumn{2}{|c|}{$\begin{array}{c}\mathscr{M}_{2} \\
\text { Baseline Policy Rule } \\
\phi_{l}=0\end{array}$} \\
\hline & & & Post. Mean & Prob.Interval & Post. Mean & Prob.Interval \\
\hline$\phi_{r}$ & {$[0,1)$} & Beta & 0.799 & {$[0.726,0.874]$} & 0.753 & {$[0.661,0.853]$} \\
\hline$\phi_{\pi}$ & $\mathbb{R}^{+}$ & Gamma & 1.353 & {$[1.142,1.549]$} & 1.703 & {$[1.457,1.946]$} \\
\hline$\phi_{y}$ & $\mathbb{R}^{+}$ & Gamma & 0.048 & {$[0.026,0.067]$} & 0.030 & {$[0.010,0.048]$} \\
\hline$\phi_{\Delta y}$ & $\mathbb{R}^{+}$ & Gamma & 0.085 & {$[0.044,0.123]$} & 0.087 & {$[0.041,0.137]$} \\
\hline$\phi_{l}$ & $\mathbb{R}$ & Normal & -0.004 & {$[-0.006,-0.002]$} & & \\
\hline Log Data Density & & & -1032.786 & & -1045.218 & \\
\hline Posterior Odds $\left(\pi_{1, T} / \pi_{2, T}\right)$ & & & $27.070 \times 10^{4}$ & & & \\
\hline
\end{tabular}

Table 11: Financial Leverage Response to Lagged Policy Rule Variation - Parameter Estimates and Posterior Odds

Criterion, which means the model with financial leverage in the lagged data rule is a better relative fit than baseline. Hence, the conclusion under the forward looking rule and the lagged data rule is the same as the current data rule, namely, the nominal interest rate does respond to financial leverage but pro-cyclically and not as part of a stabilization policy.

\subsubsection{Rule Variations and Credit Growth}

With the relevant counterpart presented in (34), the expectations based policy rule with credit growth augmentation is given by

$$
\begin{array}{r}
\hat{r}_{t}^{n}=\phi_{r} \hat{r}_{t-1}^{n}+\left(1-\phi_{r}\right)\left(\frac{\phi_{\pi}}{4}\left(\sum_{j=1}^{3} \hat{\pi}_{t-j}+E_{t} \hat{\pi}_{t+1}\right)+\phi_{y} E_{t} \hat{y}_{t+1}\right)+\phi_{\Delta y}\left(\hat{y}_{t}-\hat{y}_{t-1}+z_{t}^{*}\right) \\
+\phi_{g} \hat{g}_{t}+z_{t}^{r} .
\end{array}
$$

With the baseline in (35), the lagged data rule, adjusted for credit growth, is presented as follows,

$$
\hat{r}_{t}^{n}=\phi_{r} \hat{r}_{t-1}^{n}+\left(1-\phi_{r}\right)\left(\frac{\phi_{\pi}}{4} \sum_{j=o}^{3} \hat{\pi}_{t-j}+\phi_{y} \hat{y}_{t-1}\right)+\phi_{\Delta y}\left(\hat{y}_{t}-\hat{y}_{t-1}+z_{t}^{*}\right)+\phi_{g} \hat{g}_{t}+z_{t}^{r} .
$$

The results for the credit growth augmented forward looking and lagged data policy 


\begin{tabular}{|c|c|c|c|c|c|c|}
\hline \multirow[b]{2}{*}{ Parameter } & \multirow[b]{2}{*}{ Domain } & \multirow[b]{2}{*}{ Density } & \multicolumn{2}{|c|}{$\begin{array}{c}\mathscr{M}_{1} \\
\text { Credit Growth in Policy Rule } \\
\left|\phi_{g}\right|>0\end{array}$} & \multicolumn{2}{|c|}{$\begin{array}{c}\mathscr{M}_{2} \\
\text { Baseline Policy Rule } \\
\phi_{g}=0\end{array}$} \\
\hline & & & Post. Mean & Prob.Interval & Post. Mean & Prob.Interval \\
\hline$\phi_{r}$ & {$[0,1)$} & Beta & 0.803 & {$[0.705,0.914]$} & 0.719 & {$[0.599,0.845]$} \\
\hline$\phi_{\pi}$ & $\mathbb{R}^{+}$ & Gamma & 1.702 & {$[1.449,1.947]$} & 1.622 & {$[1.397,1.866]$} \\
\hline$\phi_{y}$ & $\mathbb{R}^{+}$ & Gamma & 0.056 & {$[0.023,0.088]$} & 0.047 & {$[0.016,0.077]$} \\
\hline$\phi_{\Delta y}$ & $\mathbb{R}^{+}$ & Gamma & 0.105 & {$[0.049,0.164]$} & 0.083 & {$[0.035,0.142]$} \\
\hline$\phi_{g}$ & $\mathbb{R}$ & Normal & -0.036 & {$[-0.057,-0.015]$} & & \\
\hline Log Data Density & & & -1044.307 & & -1043.853 & \\
\hline Posterior Odds $\left(\pi_{1, T} / \pi_{2, T}\right)$ & & & 0.635 & & & \\
\hline
\end{tabular}

Table 12: Credit Growth Response to Expectational Policy Rule Variation - Parameter Estimates and Posterior Odds

\begin{tabular}{|c|c|c|c|c|c|c|}
\hline \multirow[b]{2}{*}{ Parameter } & \multirow[b]{2}{*}{ Domain } & \multirow[b]{2}{*}{ Density } & \multicolumn{2}{|c|}{$\begin{array}{c}\mathscr{M}_{1} \\
\text { EFP in Policy Rule } \\
\left|\phi_{g}\right|>0\end{array}$} & \multicolumn{2}{|c|}{$\begin{array}{c}\mathscr{M}_{2} \\
\text { Baseline Policy Rule } \\
\phi_{g}=0\end{array}$} \\
\hline & & & Post. Mean & Prob.Interval & Post. Mean & Prob.Interval \\
\hline$\phi_{r}$ & {$[0,1)$} & Beta & 0.827 & {$[0.740,0.916]$} & 0.753 & {$[0.661,0.853]$} \\
\hline$\phi_{\pi}$ & $\mathbb{R}^{+}$ & Gamma & 1.722 & {$[1.466,1.986]$} & 1.703 & {$[1.457,1.946]$} \\
\hline$\phi_{y}$ & $\mathbb{R}^{+}$ & Gamma & 0.039 & {$[0.014,0.062]$} & 0.030 & {$[0.010,0.048]$} \\
\hline$\phi_{\Delta y}$ & $\mathbb{R}^{+}$ & Gamma & 0.118 & {$[0.059,0.184]$} & 0.087 & {$[0.041,0.137]$} \\
\hline$\phi_{g}$ & $\mathbb{R}$ & Normal & -0.026 & {$[-0.048,-0.005]$} & & \\
\hline Log Data Density & & & -1047.443 & & -1045.218 & \\
\hline Posterior Odds $\left(\pi_{1, T} / \pi_{2, T}\right)$ & & & 0.108 & & & \\
\hline
\end{tabular}

Table 13: Credit Growth Response to Lagged Policy Rule Variation - Parameter Estimates and Posterior Odds

rules "Negative" based on the Jeffreys scale for the Posterior Odds tests for relative fit and the sign on $\phi_{g}$ in both cases is negative, which is not supportive of any stabilization policy rule. The conclusion is that there is no evidence in favour of monetary policy rule response to credit growth. 


\subsection{Impulse Response Analysis - Stabilization with Credit Spreads in the Policy Rule}

The stand out result hitherto relates to the role the external finance premium plays in the central bank's monetary policy rule. The evidence demonstrates an improvement in model fit when credit spreads are introduced to the policy rule and the negative sign on the posterior point estimate is consistent with a policy maker's objective of stabilization, from a theoretical perspective. The next step is to use the full set of estimated parameters (both policy and nonpolicy) for two DSGE models, one that contains the external finance premium in the policy rule and the other that does not and simulate both models, using one standard deviation shocks. If the simulated results, based on the estimation of the full DSGE model parameter set, show stabilization of key macroeconomic variables in the presence of shocks, then this demonstrates merit in responding to credit spreads in the policy rule and may support the notation that the Fed does indeed respond to the external finance premium, in setting the policy interest rate.

The impulse responses from a shock to the external finance premium are studied to assess whether there is any empirical evidence of macroeconomic stabilization arising from a monetary policy rule that responds to the external finance premium. Impulse responses are generated for the DSGE system containing the original baseline rule (21) and are compared with those generated from the DSGE system containing the EFP augmented rule (31), to analyse effects on observed output, investment, external finance premium, net worth, policy interest rate and inflation. The shocks used for the impulse response analysis are: external finance premium shocks $z^{\mu}$, neutral technology shocks, $z^{z}$ and preference shocks, $z^{b}$.

\subsubsection{Shock to the External Finance Premium}

The first shock considered is a risk shock emanating from the financial sector, $z^{\mu}$, the shock to the external financial premium or credit spreads. This type of shock is most famously recognized during financial crises and is associated with financial system systemic risk such as in the Global Financial Crisis (GFC) or the Asian Crisis. However, the expansion and contraction of corporate credit spreads via $z^{\mu}$ shocks, is something that occurs also in more subtle magnitudes during the business cycle as well as more dramatic episodes. 
The data set used for the parameter estimates in the DSGE model for simulation includes the GFC and the DotCom crisis but the majority of the time frame includes less dramatic history such as the Great Moderation that preceded the GFC. The nature of the inquiry relates to how the central bank behaves systematically over the business cycle rather than studying specific events. Figure 1 and Figure 2 represent the impulse responses for 40 quarters for the $z^{\mu}$ for the model with both no policy rule response to the external finance premium and a policy response to the external finance premium, respectively.
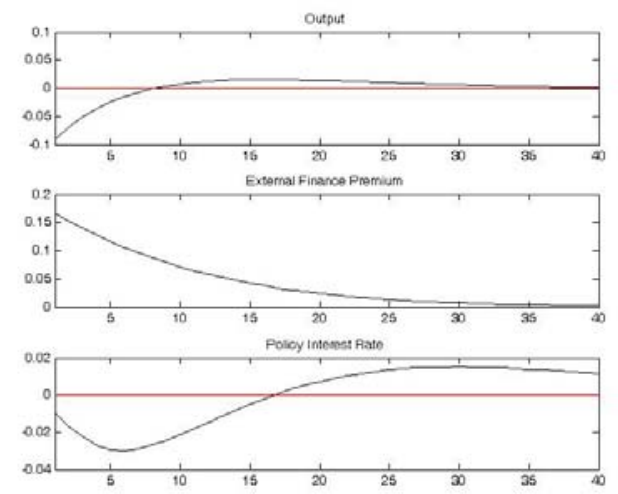
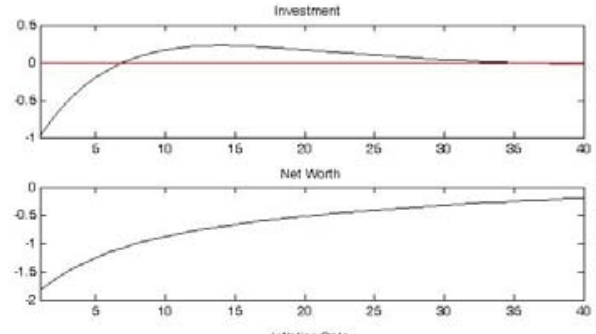

intation fasto

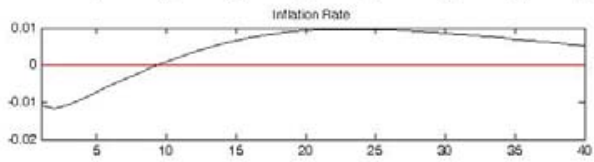

Figure 1: Impulse Response to EFP Shock with No Credit Market Factor Response
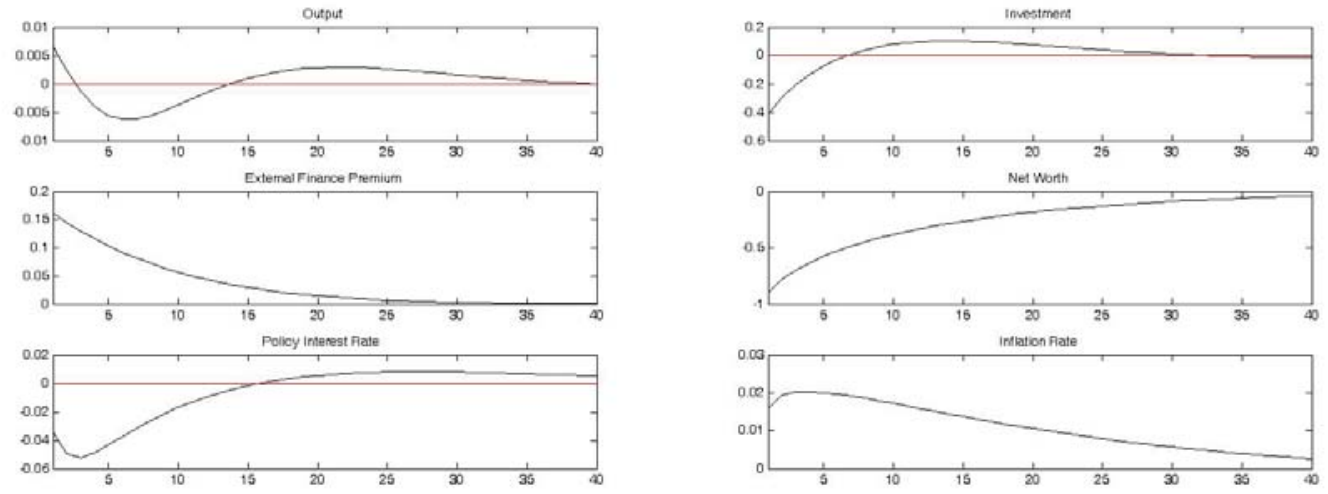

Figure 2: Impulse Response to EFP Shock with Policy Rule Responding to EFP

The impulse responses in Figure 2 clearly show the stabilization effect of the policy interest rate, responding the the external finance premium, in the presence of a EFP shock. 
Starting with the policy interest rate, in both cases, the risk shock leads to a fall in the policy interest rate due to drop in demand for capital from the rising real loan rate and thus a lower demand for loans from financial intermediaries. The fall in the policy interest rate in Figure 1 is more pronounced since the Fed lowers the policy rate in response to the increase in credit spreads. There is a slightly muted initial rise in the external finance premium and it returns to the zero baseline more quickly in Figure 2, where there is a policy response to credit spreads. Via the structural equation (8), there is a negative relationship between the external finance premium and net worth so the negative shock to net worth in Figure 2 is more muted and rises inversely with the falling normalization in the external finance premium. The quicker recovery in the external finance premium and net worth put in motion the financial accelerator more quickly in the case of policy response to credit spreads, leading to a more moderate initial response in investment and output and a quicker workout, in the presence of the shock to the external finance premium. However, the inflation rate is slightly higher. Therefore, there is compelling evidence that responding to the external finance premium in the policy rule leads to a significant degree of stabilization in the presence of a EFP shock.

\subsubsection{Stabilization under Neutral Technology Shock}

Attention now turns to the neutral technology shock and the results in Figure 3 (no policy response response to credit spreads) and Figure 4 (policy response) show much more subtle differences than the risk shocks, which directly impact the external finance premium response. The neutral technology shock does not come from the finance sector but emanates from the real economy. Nevertheless, there is some subtle evidence of stabilization. The neutral technology shock lowers the external finance premium in both cases. However in Figure 4, the policy response is to raise rates so the recovery in the policy rate to the zero line is faster than in Figure 3. Therefore, the fall in inflation is muted and the path to the zero line is faster than in the no policy case in Figure 3. Also, the positive impulse for output is initially slightly weaker in Figure 4 under policy response and the normalization to the zero line is slightly quicker. While not as pronounced as the risk shock, there is some evidence of stabilization under the DSGE model, which responds to the external finance premium in the policy rule. 

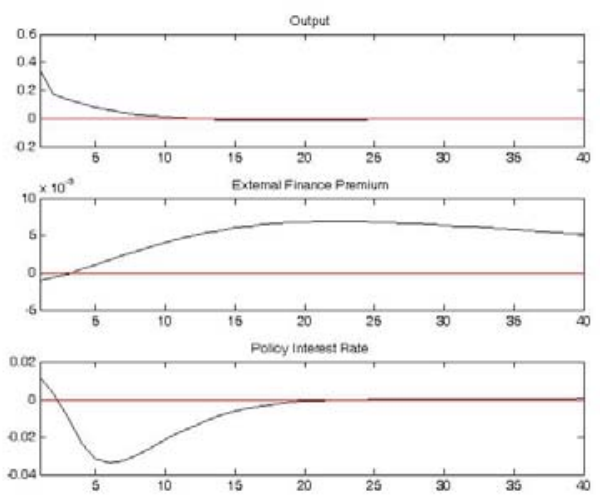

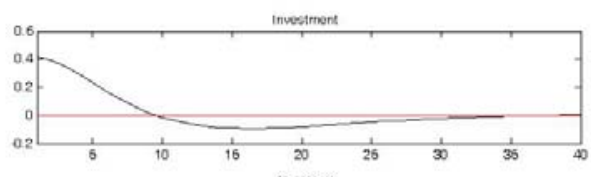

Net Worth

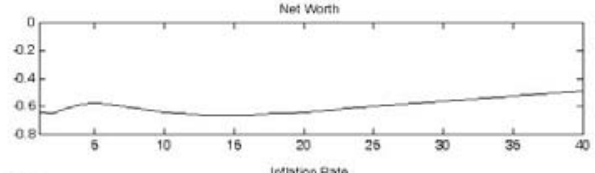

Intation Rate

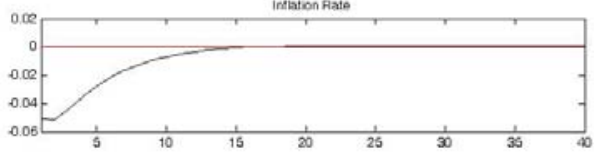

Figure 3: Impulse Response to Neutral Technology Shock with No EFP Response
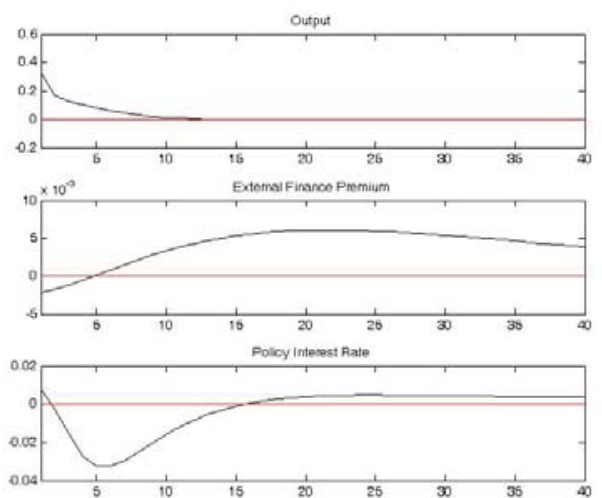
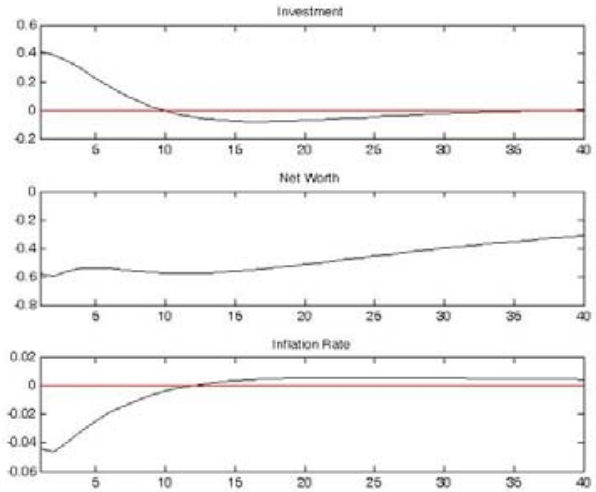

Figure 4: Impulse Response to Neutral Technology Shock with EFP Response

\subsubsection{Stabilization under the Preference Shock}

The preference shock $z^{b}$ is a positive demand shock and the differential effects on the two DSGE model impulse responses are presented in Figure 5 and Figure 6, which correspond to no response and a response to the external finance premium in the policy rule, respectively. There is very little difference in the two sets of impulse responses. In the case of the EFP shock, the shock lead directly to an effect on the policy rule containing the external finance premium. This lead to some considerable differences in the impulse responses and supported the notion that the policy rule offers stabilization merit. The technology shock does not 
directly impact the policy rule but the technology shock directly impacts the entrepreneurial sector and impacts the financial accelerator and the external finance premium augmented policy rule is affected via this mechanism. The preference shock, however, does not directly impact the policy rule and does not directly affect the financial accelerator so may be too removed to have a meaningful impact on the impulse responses, so no conclusions can be made regarding stabilization.
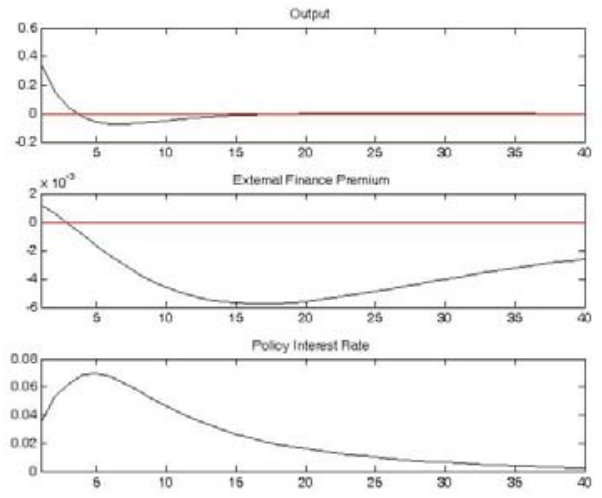

Figure 5: Impulse Response to Preference Shock with No EFP Response
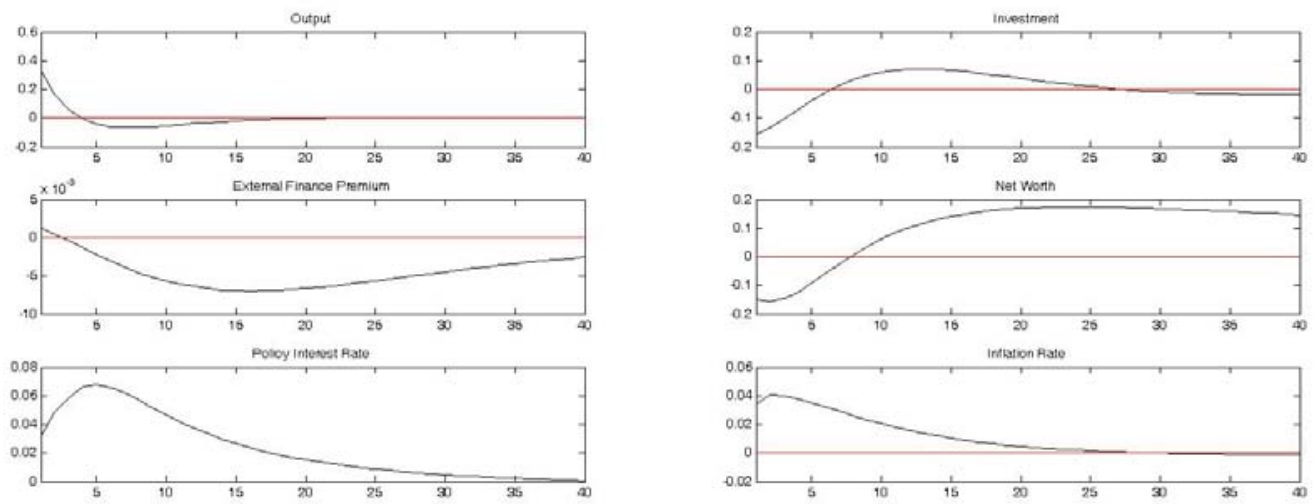

Figure 6: Impulse Response to Preference Shock with No EFP Response 


\section{Conclusions}

A financial friction augmented New Keynesian DSGE model is estimated for the United States using Bayesian methods. Posterior odds tests for model comparison are used to evaluate competing models that contain alternative monetary policy rules, where in turn the three credit factors: credit spreads, financial leverage and credit growth are evaluated. The central question in this paper is whether the US monetary authority responded to credit market factors in setting the policy interest rate. The most important result is the US Fed responded to credit spreads in setting the policy rate over the period 1985-2008. The negative sign on the estimated EFP response parameter and the fact that the range of the probability interval is fully negative, together with the posterior odds test for model fit and that these results are robust to various specifications of the policy rule, is most compelling evidence. The impulse response analysis also confirms that credit spreads offer stabilization benefits, over a model where the associated monetary policy rule does not respond to credit spreads. It is also found that while financial leverage improves model fit when included in the policy rule, the response is pro-cyclical, which can be interpreted as the monetary authority actually fuelling bubbles, which is not a feature of stabilization policy. Finally, there is no evidence that the policy interest rate responded to credit growth. 


\section{References}

Adjemian, S., H. Bastani, F. Karame, M. Juillard, J. Maih, F. Mihoubi, G. Perendia, J. Pfeifeer, M. Ratto, and S. Villemot, "Dynare: Reference Manual Version 4," Dynare Working Paper Series: Working Paper no. 1, jan 2014. CEPREMAP.

An, S. and F. Schorfheide, "Bayesian Analysis of DSGE Models," Econometric Reviews, 2007, 25, 113-172.

Bernanke, B.S., M. Gertler, and S. Gilchrist, "The Financial Accelerator in a Quantitative Business Cycle Framework," In Handbook of Macroeconomics, ed. J.B. Taylor and M. Woodford, Vol. 1C, 1999, pp. 1341-1393. Amsterdam, North-Holland.

Bullard, J. and K. Mitra, "Determinacy, Learnability, and Monetary Policy Inertia," Journal of Money, Credit and Banking, 2007, 39 (5), 1177-1212.

Calvo, G.A., "Staggered Prices in a Utility Maximizing Framework," Journal of Monetary Economics, 1983, 12, 383-398.

Christiano, L., R. Motto, and M. Rostagno, "Financial Factors in Economic Fluctuations," European Central Bank Working Papers, 2010, (1192).

Curdia, V. and M. Woodford, "Credit Spreads and Monetary Policy," Journal of Money, Credit and Banking, 2010, 42, 3-35.

Gilchrist, S., A. Ortiz, and E. Zakrajsek, "Credit Risk and the macroeconomy: Evidence from an estimated DSGE model," Proceedings, FRM/JMCB Conference, Financial Markets and Monetary Policy, 2009.

and E. Zakrajsek, "Monetary Policy and Credit Supply Shocks," IMF Economic Review, June 2011, 59 (2), 195-232.

_ and _ _ "Credit Spreads and Business Cycle Fluctuations," American Economic Review, June 2012, 102 (4), 1692-1720.

__ and Zakrajsek E. Ortiz A., "Credit market shocks and economic fluctuations: Evidence from corporate bond and stock markets," Journal of Monetary Economics, 2009, 56 (4), 471-493. 
Henderson, D. and W. McKibbin, "A comparison of some basic monetary policy regimes for open economies: implications of different degrees of instrument adjustment and wage persistence," Carnegie-Rochester Conference Series on Public Policy, December 1993, 39 (1), 221-317.

Hirose, Y., "Monetary Policy And Sunspot Fluctuations In The United States And The Euro Area," Macroeconomic Dynamics, 2013, 17, 1-28.

and T. Kurozumi, "Do investment-specific technological changes matter for business fluctuations? Evidence from Japan.," Pacific Economic Review, 2012, 17 (2), 208-230.

Jeffreys, H., The Theory of Probability, third ed., Oxford, 1961.

Kaihatsu, S. and T. Kurozumi, "Sources of business fluctuations: technology or financial shocks," Review of Economic Dynamics, 2014, 17, 224-242.

Lubik, T.A. and F. Schorfheide, "Do Central Banks Respond to Exchange Rates? A Structural Investigation," Journal of Monetary Economics, 2007, 54, 1069-1087.

Schwartz, G., "Estimating the dimension of a model," Annals of Statistics, 1978, 6, 461464.

Smets, F. and R. Wouters, "Shocks and frictions in US business cycles: A Bayesian DSGE approach," American Economic Review, 2007, 97 (3).

Taylor, J.B., "Discretion versus Policy Rules in Practice," 1993, (39), 195-214. CarnegieRochester Conference Series on Public Policy. , "Monetary Policy and the State of the Economy," 2008. Testimony before the Committee on Financial Services, U.S. House of Representatives. 